\title{
Recruitment of Env to the HIV-1 T cell virological synapse by targeted and
}

\author{
sustained Env recycling
}

\author{
Lili Wang $^{\mathrm{a}}$, Alice Sandmeyer ${ }^{\mathrm{b}}$, Wolfgang Hübner ${ }^{\mathrm{b}}$, Hongru Li ${ }^{\mathrm{a}}$, Thomas Huser $^{\mathrm{b}}$, Benjamin K. \\ Chen $^{a}$ \\ ${ }^{a}$ Department of Medicine, Division of Infectious Disease, Immunology Institute, Mount Sinai \\ School of Medicine, New York, New York 10029; ' Biomolecular Photonics, Department of \\ Physics, University of Bielefeld, Bielefeld, Germany 33615
}

\section{ABSTRACT}

HIV-1 infection is enhanced by cell-cell adhesions between infected and uninfected T cells called virological synapses (VS). VS are initiated by the interactions of cell-surface HIV-1 envelope glycoprotein (Env) and CD4 on target cells and act as sites of viral assembly and viral transfer between cells. To study the process that recruits and retains HIV-1 Env at the VS, a replication-competent HIV-1 clone carrying an Env-sfGFP fusion protein was designed to enable live tracking of Env within infected cells. Using surface pulse-labeling of Env and fluorescence recovery after photobleaching (FRAP) studies, we observed targeted accumulation and sustained recycling of Env between the endocytic recycling compartment (ERC) and the VS. We observed dynamic exchange of Env at the VS while the viral structural protein, Gag, was largely immobile at the VS. The disparate exchange rates of Gag and Env at the synapse indicate that retention of Env is not likely to be maintained by entrapment into an immobile Gag lattice or through immobilizing interactions with CD4 on the target cell. A FRAP study of an Env endocytosis mutant showed that recycling is required for the rapid exchange of Env at the VS. We conclude that the mechanism of Env accumulation at the VS and incorporation into nascent particles involves continuous internalization and targeted secretion rather than irreversible interactions with the budding virus. 


\section{INTRODUCTION}

31 The HIV-1 envelope glycoprotein (Env) plays crucial roles as the surface glycoprotein on

32 the virus particle, mediating virus binding, fusion and entry, as well as in initiating the formation

33 of cell-cell adhesions that facilitate viral transmission, called virological synapses (VS) (1-3).

34 HIV-1 can infect cells through cell-free virus, or through cell-to-cell routes which involve direct

35 transfer of virus across a VS. HIV-1 Env is the surface antigen exposed on the surface of the

36 cell or on virus particles where it can engages its main target CD4. HIV-1 is an enveloped virus

37 that assembles and buds from the plasma membrane in a process mediated by the core

38 structural protein Gag (4). An endocytic trafficking pathway helps to package Env into newly

39 formed virus particles (5-7). The expression of Env at the cell surface renders infected cells

40 susceptible to antibody detection, and while many antibodies against Env can block the

41 formation of virological synapses, they are less efficient at blocking cell-to-cell infection than

42 they are at blocking cell-free infection (8-12).

43 The biogenesis of HIV-1 Env begins at ribosomes on the rough endoplasmic reticulum (ER)

44 where newly synthesized Env is glycosylated into precursor gp160 to form homotrimers (13).

45 The cleavage of gp160 occurs in the Golgi apparatus by furin or furin-like proteases and results

46 in two non-covalently associated peptides: a cell surface glycoprotein, gp120, and a

47 transmembrane glycoprotein, gp41 $(14,15)$. Env trimers travel through the secretory pathway

48 to reach the plasma membrane, and then are quickly recycled from the cell surface (16-20).

49 This contributes to the very low number of Env glycoproteins on the cell surface. Lentivirus gp41

50 has a long intracytoplasmic C-terminal tail compared to other retroviruses (21). A membrane-

51 proximal tyrosine-based sorting signal $\mathrm{YxxL}$ in the gp41 C-terminus interacts with the AP-2 to

52 promote the internalization of Env (22-24). Env recycling from the cell surface to the endocytic

53 recycling compartment $(E R C)$ is a prerequisite for Env incorporation $(6,7)$. Proper incorporation

54 of Env into viral particles also requires gp41 C-terminal sequences. The outward trafficking of 
55 Env from ERC to virus assembly area is mediated by C-terminal tyrosine-based motif YW795 56 (5).

HIV-1 cell-to-cell transmission leads to the efficient transfer of virus and infection $(3,10,25)$

58 and mediates resistance to neutralization (8-12). Cell-to-cell transmission promotes viral

59 diversity by supporting the co-transmission of multiple copies of HIV-1 per transmission event

60 (26-28) and is proposed to play a role in escape from immune responses or may promote the

61 evolution of drug resistance in settings of suboptimal therapy $(9,29,30)$. The HIV-1 VS is an

62 example of polarized viral transmission, where the assembly and release of Env and Gag are

63 directed toward the receiving target cell, which internalizes the virus through an endocytic

64 pathway $(31,32)$. At the VS, HIV-1 Gag, Env and CD4 localize to the site of cell-cell contact in

65 an actin-dependent manner (3). Recruitment of Gag and Env protein and their transfer through

66 VS occurs in a dynamic process following cell-adhesion (33, 34). Env-CD4 interaction is

67 required for VS formation. Blocking the interaction of Env and CD4 with antibodies inhibits VS

68 formation (10). During the formation of a VS, Env is observed to accumulate at the VS,

69 however, the mechanisms of enrichment of Env at the VS are not well characterized. The

70 extent to which Env diffuses laterally, is recruited to the VS from surface pools or may be

71 concentrated by a secretory pathway that targets the VS is unclear.

72 The fusion of proteins with the green fluorescent protein enables live tracking of the protein

73 within the cell (35). However, the relatively large size of GFP and its derivatives (30kD) requires

74 careful consideration of the site of insertion to maintain the function of the protein of interest.

75 Prior Env-GFP fusions have been expressed outside of the full proviral context or required 76 complementation of WT Env to support viral replication (33). In order to preserve Env function, a

77 strategy of insertion of GFP into the fourth variable loop was intended to yield a full-length

78 infectious HIV clone with a functional Env (36). 
Short peptide motifs in the Env cytoplasmic tail (CT) can control surface Env levels, direct

80 incorporation of Env into viral particles, and can impact the conformation of the surface (36)

81 domain of Env, which can further modulate Env fusogenic potential $(37,38)$. In this study, we

82 engineered an infectious HIV-1 carrying a fluorescent-Env to observe the de novo expression of

83 Env in an infected cell and track Env accumulation and turnover during VS formation. We

84 followed the turnover rate of Env trafficking at the VS using fluorescence recovery after 85 photobleaching (FRAP), which revealed that surface Env is constitutively recycled and the 86 residence time at the cell surface is short lived measured in minutes, even at sites of high 87 surface accumulation.

\section{RESULTS}

\section{Engineering an infectious HIV carrying a sfGFP insertion into the Env V4 or V5 domains}

91 To study the trafficking of Env to the VS we set out to design a fluorescent protein-tagged

92 Env that is compatible with efficient packaging and viral membrane fusion. To minimize

93 disruption of Env structural stability, we inserted a superfolder allele of GFP (39) directly into the

94 HIV-1 Env coding sequences at selected points of V4 or V5 domain, which have previously

95 been described as producing fluorescent Env (Fig.1A). The four HIV-1 clones carrying the Env-

96 GFP fusion proteins produced similar levels of virus compared to the parent clone, HIV NL4-3

97 (Fig.1B). Three constructs produced virus with 25 to $50 \%$ of infectivity relative to HIV NL4-3

98 with a wild-type Env (Fig.1C). Western Blotting of cells producing HIV-1 Env-V4.1-sfGFP, HIV-1

99 Env-V4.2-sfGFP and HIV-1 Env-V5.2-sfGFP revealed the expected increase in size of the Env

100 glycoprotein in the cell lysates as compared to WT Env from HIV-1 NL4-3 (Fig.1D). We noted

101 that in cell lysates recombinant Env was processed to gp120-GFP fusion, but with a moderately

102 lower efficiency. The recombinant Envs, Env-V4.1-sfGFP, Env-V4.2-sfGFP and Env-V5.2- 
103 sfGFP were also packaged efficiently onto virus particles. One recombinant construct Env-

104 V5.3-sfGFP failed to produce full-sized Envelope proteins.

105 We next examined the efficiency of the four different HIV Env-sfGFP constructs to infect T

106 cell lines. Infection of the highly permissive MT4 cell line was robust with cell-free virus showing

107 high infectivity (Fig. 1E). Infection of Jurkat cells was lower in magnitude, with greater infection

108 with HIV carrying V4.2-sfGFP followed by V4.1-sfGFP and V5.2-sfGFP (Fig. 1E). In both MT4

109 cells and in Jurkat cells, efficiency of infection of HIV V5.3-sfGFP was very low (Fig. 1E). To test

110 if the four HIV clones carrying the Env-GFP fusion proteins can mediate spreading infection,

111 Jurkat cells transfected with each of clones were co-cultured with MT4 cells or Jurkat cells. The

112 spread of virus from transfected donor cells into target cells was measured using flow cytometry

113 (Fig. 1F). The infection spread efficiently in MT4 cells with HIV-1 Env-V4.2-sfGFP replicating to

114 a high peak titers as compared to wild type Env construct NL-sfGI, but with slower kinetics. In

115 Jurkat cells, the HIV Env-V4/V5 sfGFP constructs all supported a spreading infection albeit with

116 a lower efficiency compared with wild type Env construct NL-sfGl (Fig. 1G).

\section{Imaging HIV-1 carrying fluorescent Env constructs}

118 To study the localization of HIV Gag and Env simultaneously during cell-to-cell spread of HIV-

119 1, we created a series of three dual fluorescent HIV clones carrying a sfGFP fluorescent Env and

120 a mCherry fluorescent Gag. We performed immunofluorescence staining of cells infected with

121 HIV-1 Env V4.2 sfGFP-Gag-iCherry, carrying the Env V4.2 sfGFP, the chimeric Env which

122 maintained highest infectivity, to compare the localization of V4.2-sfGFP Env to WT Env.

123 Monoclonal antibody 2 G12 binds to a non-conformational epitope and showed colocalization with

124 Env-V4.2-sfGFP fluorescence in a sample cell (Fig. 2A-E). V4.2-sfGFP Env is abundantly

125 expressed in cytoplasmic compartments, with the highest fluorescence shown in a peri-nuclear

126 area, consistent with wild type Env distribution reported previously (16). To assess the 
127 distribution of Env and Gag relative to the plasma membrane, we performed structured

128 illumination, super resolution imaging (Deltavision OMXv4.0 BLAZE) of Jurkat cells transfected

129 with HIV-1 Env V4.2 sfGFP-Gag-iCherry and stained with a plasma membrane dye, Cell Mask

130 deep Red (Fig. 2F-I). The predominant signal for Env was found in an intracellular compartment

131 consistent with the trans-Golgi network (TGN), with minimal expression at the cell surface. A line

132 projection of the fluorescence intensity across the plasma membrane revealed that Gag was

133 located at the inner leaflet of plasma membrane. Env was not obviously enriched at the plasma

134 membrane (Fig. 2F-J). Surface staining of Env on live cells expressing HIV Env-V4.2-sfGFP with

135 anti-GFP antibody, showed puncta of Env at relatively low density (Fig. 2K-M). A time-lapse

136 study of the kinetics of de novo expression of HIV Env-V4.2-sfGFP was performed using a

137 confocal fluorescence imaging system from $6 \mathrm{~h}$ to $26 \mathrm{~h}$ post transfection (Fig. 2N). Env

138 expression in the transfected cells peaked at 16-20h post transfection and declined thereafter

139 (Supplemental Movie S1). Individual cells showed a similar peak expression of Env-sfGFP in the

140 cells in the imaging field (Supplemental Fig. 1). To examine the distribution of HIV Env-V4.2-

141 sfGFP during the formation of virological synapses, we co-cultured Env-V4.2-sfGFP transfected

142 Jurkat cells with primary $\mathrm{CD}^{+}$target cells. Accumulation of Env at the junctions between HIV

143 Env-V4.2-sfGFP transfected Jurkat cells and uninfected primary CD4+ T cells was observed (Fig.

144 2O-P). In primary $\mathrm{CD}^{+}$cells transduced with Env-V4.2-sfGFP viruses, a similar synaptic

145 accumulation of Env was seen at the junction between the HIV-expressing primary T cell and the 146 target primary T cell (Fig. 2Q).

147 A dual fluorescent protein-expressing HIV with Gag-iCherry and Env-sfGFP participates 148 in VS-mediated HIV transfer

149 HIV-1 constructs that carry a Cherry fluorescent protein inserted into Gag are not infectious, 150 but generate highly fluorescent virus particles and participate in cell-to-cell transfer (10, 40). To 151 determine if the fluorescent Env constructs are capable of participating in cell-to-cell HIV 
152 transfer across virological synapses, we generated dual fluorescent HIV which carry two

153 fluorescent protein tags, Cherry and sfGFP, inserted into Gag and Env, respectively. The dual

154 fluorescent viruses make abundant virus particles when transfected (Fig. 3A). The infectivity of

155 these constructs in reporter cell lines are shown in Fig. 3B. These constructs maintained the

156 ability to form VS and transfer Env and Gag into a target cell (Fig. 3C). HIV V4.2 sfGFP-Gag-

157 iCherry expressing cells were tested for their ability to mediate HIV transfer across VS and

158 transfer of fluorescent Gag and Env was observed (Fig. 3C). When the cell co-culture is treated

159 with CD4 antibody, Leu3a, which can block CD4 engagement with Env, both Gag and Env

160 transfer are blocked (Fig. 3C and D). Confocal fluorescence microscopy of the dual fluorescent

161 constructs in Jurkat T cells and primary CD4+ T cells enabled visualization VS where both Env

162 and Gag were colocalized (Fig. 3E, upper panel). In an example of a cell forming two virological

163 synapses, one synapse showed both Gag and Env at the cell-cell junction, and the other

164 showed accumulation of only Gag at the cell-cell junction (Fig. 3E, lower panel). During the

165 imaging of virological synapses, Gag and Env colocalization at a virological synapse was more

166 frequently observed soon after cell-cell mixing, and over time, the frequency of VS with only

167 Gag concentrated at the VS increased. Images of VSs showed that Env and Gag were more

168 frequently co-localized at 1 hour post coculture (82.4\%); while after 3 -hour coculture, the

169 colocalization of Env and Gag at VS was observed in a lower percentage of cells (37.5\%). Over

170 time, both Gag and Env were observed to transfer into a target cell. The majority of fluorescent

171 HIV proteins transferred into the target cells showed colocalization of Env and Gag, whereas

172 some puncta appeared to represent the transfer of only Gag or only Env (Fig. 3G). Cotransfer

173 of Env and Gag may be indicative of infectious virus, while the transfer of only Gag or only Env

174 may represent the uptake of non-infectious viral antigen.

175 Pulse-Chase labeling of surface Env tracks endocytosis and relocalization to the VS. 
The Env-CD4 interaction is a prerequisite of VS formation, but how Env is recruited to the

177 VS is not clear. Prior imaging studies indicate that Gag is recruited from membrane associated

178 pools and diffuses laterally into the VS (34). To examine the pathway of Env recruitment, we

179 labeled cell surface Env with an anti-GFP fluorophore conjugated antibody and performed a

180 pulse-chase imaging study to follow movements of surface-localized Env over time. Cell surface

181 Env of a Jurkat cell nucleofected with HIV-1 V4.2-Gag-iCherry was visualized by staining at $4^{\circ} \mathrm{C}$

182 (Fig. 4A). Env is known to be quickly endocytosed from the cell surface (13). After warming

183 cells to $37^{\circ} \mathrm{C}$, cells were fixed after 5, 10 and 20 minutes to monitor the movement of pulse

184 labeled Env. The surface Env stained cells were separated into two groups: one group that was

185 mixed with target cells immediately after surface staining, and co-cultured at $37^{\circ} \mathrm{C}$ for 30

186 minutes. The second group was allowed to recover at $37^{\circ} \mathrm{C}$ for 30 minutes, then mixed with

187 target cells for another 30 minutes. Both groups of cells were fixed afterwards and imaged with

188 confocal microscopy. In group 1, surface labeled Env was mainly found in endocytic recycling

189 compartments (ERC), while at the synapse area, no labeled Env was observed (Fig. 4C). In the

190 second group, recycled surface Env localized mainly to the cell-cell junction when virological

191 synapses were observed (Fig. 4D). These results indicate that surface-labeled Env can be

192 endocytosed into the ERC, and then traffics specifically to the VS.

193 Fluorescence recovery after photobleaching (FRAP) of HIV Env V4.2 sfGFP-Gag-iCherry

\section{4 at VS reveals constitutive turnover of Env at the VS}

195 The results above indicate cell surface Env can be internalized into the ERC, reappear at

196 cell surface, and then accumulate at the VS. How Gag recruitment may influence Env at the VS

197 is not known. It is possible for instance that the recruitment of Gag to the VS may trap Env

198 during its incorporation onto nascent virus particles, or that the interaction of Env with CD4 may

199 immobilize it at the cell surface. To simultaneously track the kinetics of Env and Gag

200 recruitment to the VS, we performed fluorescence recovery after photobleaching (FRAP) 
201 experiments with HIV V4.2 Env sfGFP-Gag-iCherry to measure the rate of turnover of Env and

202 Gag at VS. We identified cells with a VS that showed both Gag and Env colocalized at the cell

203 contact area. Half of the VS was photo-bleached, and the other half of the VS allowed

204 segmentation of the VS and measurement of recovered fluorescence over time. Additional

205 unbleached areas were tracked over time as a control to determine the basal rate of photodecay.

206 With a smaller VS, the entire VS was bleached, and a nearby area was used as a control. As

207 shown in Fig. 5A-1, the white square indicates the bleached area, and the yellow closed region

208 is the selected region of interest $(\mathrm{ROI})$. ROI-1 is the bleached synapse area, while ROI-2 is the

209 unbleached control area. A steady recovery of Env intensity was observed within about 200

210 seconds, while in the same time period, there was minimal fluorescence recovery of Gag. Four

211 additional FRAP studies on four different virological synapses were performed (Fig. 5A-2 to A-5,

212 see Supplemental Movies 2-6). The recovery curve of Env was fitted to a one-phase

213 exponential association function for each ROI (Fig. 5A-1 to A-5, right panels, ROI curves). The

214 Env intensity before bleaching was set to $100 \%$. The maximum recovery over the time frame of

215 imaging was used to calculate an immobile fraction which differed between the different

216 samples (Fig. 5B). In all the VS we observed, Gag fluorescence recovery was not observed,

217 while Env fluorescence recovery occurred within 2-3 minutes with the half recovery time (Fig.

$2185 \mathrm{C}$ ), indicating a much greater rate of Env turnover at the VS relative to Gag.

220 High turnover of Env at the VS requires endocytosis of Env using a membrane proximal

\section{1 tyrosine Y712}

222 The gp41 C-terminal membrane-proximal tyrosine 712 in a YXXL AP-2 binding-motif is 223 important for the internalization of surface Env through AP-2 mediated endocytosis (22). To test 224 if surface Env endocytosis is required for synapse recruitment or turnover of Env at the VS, we 225 introduced the Y712A point mutation into the viral clone, HIV Env-V4.2-sfGFP. HIV-1 with the 
226 Env Y712A mutation is reported to be less infectious as compared to wild type virus (38). We

227 performed a T cell-to-T cell viral transfer assay using Jurkat donor cells and primary CD4 T cells

228 as target cells and observed that cell-to-cell transfer of Env is increased by 3-fold in $\mathrm{Y} 712 \mathrm{~A}$

229 mutant relative to non-mutated virus in 3-hour co-culture (Fig. 6A). A separate cell-to-cell

230 infection assay was performed to measure productive infection between HIV-expressing Jurkat

231 cells and primary CD4 T cells. In this assay, both the wild type and the Y712A virus spread with

232 similar efficiencies (Fig. 6B). In highly permissive MT4 cells, the Y712A virus spread with a

233 slightly higher rate than wild type in 7-day productive infection (Fig. 6C). We next performed live

234 imaging to see if the mutation which disrupts Env endocytosis from cell surface permits VS

235 formation and accumulations of Env and Gag at the cell-cell junctions. We readily observed VS

236 formation with high levels of Env recruitment to the synapse. When conducting FRAP studies

237 we found that the Env recovery was dramatically decreased in the HIV-1 Env V4.2-Y712A-

238 sfGFP when compared to the non-mutated clone (Fig. 6D-1). Four additional FRAP experiments

239 were performed on virological synapses formed by HIV-V4.2-Y712A-sfGFP (Fig. 6D-2 to D-5).

240 There was minimal or no recovery of Env or Gag observed over 5 minutes after photobleaching.

241 Videos of all five virological synapses are in Supplemental Movies 7-11. Based on the extent of

242 the fluorescence recovery the immobile fraction of Env was calculated, which was close to $100 \%$

243 in all the examples (Fig. 6E).

\section{Discussion}

246 In this study, we have constructed a fluorescent Env-carrying HIV clone that is capable of 247 viral entry and productive infection in T cells in cell culture. The fluorescent Env fusion protein 248 resembles wild type Env in its subcellular distribution and is very efficient in its ability to 249 participate in VS formation and cell-to-cell infection. This is the first description of a HIV-1 clone 250 encoding a fluorescent Env that is autonomously infectious. It enables live tracking of Env and 
251 its exchange between subcellular compartments during its recruitment to the VS. This tool

252 makes it possible to observe Env distribution and trafficking within the context of productive

253 infections, and in the absence of helper virus. We employ it here to test models for how Env

254 trafficking contributes to viral spread between cells and supports the production of infectious 255 virus particles.

256 Immunofluorescence with monoclonal antibody, 2G12, which recognizes a carbohydrate 257 epitope, revealed that the localization of V4.2 Env resembles native HIV-1 Env. With super258 resolution imaging and surface Env staining, we observed that the majority of Env is expressed 259 in internal compartments, the endoplasmic reticulum, the Golgi apparatus, and endosomal 260 compartments. As previously appreciated, cell surface Env represents a small fraction of total

261 Env in the cell, and the results of our fluorescence microscopy also show very low surface Env

262 levels (41-43), which also appears to correlate with the low Env density on viral particles (7-14

263 Env trimer/particle) $(44,45)$. When imaging VS, the fluorescent Env construct revealed

264 increased concentrations of surface-targeted Env at cell-cell contact zones. This localization is

265 consistent with the earliest VS imaging studies on fixed samples that indicate that Env

266 accumulates to the VS area through actin dependent processes (3). In our study, cell surface

267 Env that was not localized to the VS was only readily observed after amplification with

268 fluorescent secondary antibodies. When visualized with GFP alone, V4.2 Env density at the cell

269 surface was relatively sparse and evenly distributed, with no obvious areas where Env is pre-

270 accumulated prior to VS formation (Fig.2 K-M and Fig.4 A).

271 The Env distribution before and after VS formation exhibits two different patterns diffuse versus

272 focal. These patterns may represent different secretory pathways that can be polarized to traffic

273 when cells are engaged in immunological synapses (46-48). The initial broad distribution of Env

274 on the cell surface occurs prior to target cell engagement, and retargeting of the recycled Env to

275 the VS appears to occur following CD4 engagement and may facilitate efficient particle 
276 incorporation. Evidence of VS-targeted Env trafficking can be observed prior to accumulation of

277 Gag at the VS. When an infected cell is attached to an uninfected target cell, Env accumulation

278 can be observed within minutes after cell attachment (33).

279 To explore the relationship of Gag and Env during the formation of VSs, a dual-fluorescent 280 virus carrying Gag-iCherry and Env-V4/V5-isfGFP fusion proteins was studied. The dual

281 fluorescent construct can also efficiently engage in cell-to-cell transfer of HIV-1. The ability to 282 mediate cell-to-cell HIV transfer indicates that the CD4 binding sites of these constructs are fully 283 functional, and signaling events prior to and during VS formation are intact. Using this 284 construct, a surface labeled Env pulse-chase experiment indicated that the display of Env on 285 cell surface is followed by internalization and subsequent concentration at the VS. In cases 286 where an Env:CD4 dependent adhesion was formed between an infected and uninfected T cell, 287 the labelled Env appeared to be directionally targeted to the cell-cell contact site with minimal 288 signal observed away from the VS (Figure 4D). We suggest that Env functions initially as a cell289 adhesion molecule and "detector" of target cell engagement, and then subsequently signaling 290 from the cell-cell adhesion determines the site of polarized egress.

291 Early confocal imaging studies revealed the VS as a site where button-shaped 292 accumulation of Gag formed at the adhesive junction between an infected cell and a target cell 293 (34). Electron microscopy of the virological synapse revealed Gag accumulation in electron 294 dense crescents forming a tight lattice at the VS $(32,34)$. Recruitment of Gag to the VS occurs 295 from the lateral migration of plasma membrane-targeted Gag that moves towards the site of 296 cell-cell contact site over minutes (34). FRAP studies here show that at a late stage of VS 297 formation, after Gag synaptic button is established, Gag is largely immobile, and shows no 298 recovery after photobleaching at the VS. This consistent with a largely irreversible incorporation 299 of Gag into nascent budding particles (49). Compared to Gag, Env can also be observed at 300 cell-cell contact area but at a lower relative concentration (Fig. 3F). A proposed model for Env 
301 incorporation into a budding virus particle is that it may be mediated by "trapping" of Env with its 302 long cytoplasmic tail becoming encumbered in the 2-dimensional Gag lattice (50). However, in 303 contrast to Gag at the VS, which is not exchanging with other pools of Gag in the cell, a large 304 majority of Env continues to exchange with intracellular pools even after stable VS formation.

305 This ability to exchange freely may indicate that a large fraction of Env is incorporated after Gag 306 crescent formation at a late stage of assembly, where is does not get encumbered by the 307 budding Gag lattice. This could be consistent with a recent superresolution imaging study 308 suggests that Env is packaged at a late-stage of assembly and is localized with a distribution 309 biased toward the necks of budding viruses (51).

310 In our FRAP studies (Fig. 5), the majority of Env at the bleached area recovered within 311 minutes of photobleaching with some minor differences in the final immobile fraction for Env.

312 This indicates the while most Env is continuously recycling to the VS a relatively small, variable

313 fraction can be immobilized at the VS. The state of the cell, the stage of VS formation and the

314 size of the VS all may contribute to these differences in the immobile fraction. The biosynthesis

315 of HIV Env and Gag occur through different pathways. In this paper, our FRAP studies indicate

316 that the forces that maintain Gag and Env at the VS are distinct. They reveal that physically

317 they are not part of a stable complex during VS formation. The high degree of recovery after

318 FRAP also indicate that a majority of Env is not held in place at the VS by the interaction with

319 CD4 on the target cell. The results also indicate that the interaction between Env and CD4 at

320 VS is reversible and mediated by a state that does not yet trigger viral membrane fusion.

321 We characterized an endocytic Env mutant and performed FRAP at the VS and observed that

322 Env could still accumulate at the VS, however, the recycling of Env to the VS was not observed.

323 This shows that blocking the endocytosis of Env with a Y712A mutation abolishes the turnover

324 of Env at the VS. In this case, the accumulation of Y712A Env at the VS may be driven by the

325 high concentration of Env at the cell surface. Truncation mutants in the C-terminal tail of Env or 
326 elimination of the main endocytic motif, Y712, allow high levels of Env to be displayed on cell

327 surface $(20,24)$. An intact cytoplasmic tail is required for incorporation into the "neck" of the

328 emerging budding virus and it is suggested that Env that are missing the CT are passively

329 incorporated into viral particles (51). In our experiments, the Y712A endocytosis mutant leads to

330 more viral transfer through the VS, though shows limited impact on the overall infectivity. This

331 mutant can display different phenotypes depending upon the cell line it is tested in though in

332 general it is still infectious (52). Together these data indicate that recycling is dispensable for

333 VS formation, transfer and infection. We therefore speculate that a major role of recycling of

334 Env at the VS lies in immune evasion: keeping surface Env density low to escape from immune

335 surveillance (53) (54). Other studies from our group have shown Y712A mutants can also

336 impact Env cell surface conformation and modulate the ability of broadly neutralizing

337 monoclonal antibodies to neutralize cell-to-cell infection (55).

338 In summary these imaging studies support an emerging model of HIV-1 cell-to-cell infection,

339 where Env traffics between the cell surface and the ERC before being packaged onto a budding

340 virus particle (Fig. 7). An initial transient phase of exposure at the cell surface participates in the

341 detection of the target cell. Subsequently Env that is recycled from surface to ERC, is

342 redirected specifically to the VS, where Env is incorporated into virus. Dynamic trafficking of

343 Env supports initial VS formation and enables VS to form under conditions where surface Env

344 concentrations are maintained at very low levels. The process of recruitment to the VS is

345 therefore optimized to reduce promote efficient transfer of virus from cell to cell while

346 maintaining minimal surface expression of the dominant viral surface antigen. 


\section{References:}

1. Owens RJ, Dubay JW, Hunter E, Compans RW. 1991. Human immunodeficiency virus envelope protein determines the site of virus release in polarized epithelial cells. Proc Natl Acad Sci U S A 88:3987-91.

352 2. Sattentau Q. 2008. Avoiding the void: cell-to-cell spread of human viruses. Nat

353 Rev Microbiol 6:815-26.

3. Jolly C, Kashefi K, Hollinshead M, Sattentau QJ. 2004. HIV-1 cell to cell transfer across an Env-induced, actin-dependent synapse. J Exp Med 199:283-93.

4. Gheysen D, Jacobs E, de Foresta F, Thiriart C, Francotte M, Thines D, De Wilde M. 1989. Assembly and release of HIV-1 precursor Pr55gag virus-like particles from recombinant baculovirus-infected insect cells. Cell 59:103-12.

5. Qi M, Chu H, Chen X, Choi J, Wen X, Hammonds J, Ding L, Hunter E, Spearman P. 2015. A tyrosine-based motif in the HIV-1 envelope glycoprotein tail mediates cell-type- and Rab11-FIP1C-dependent incorporation into virions. Proc Natl Acad Sci U S A 112:7575-80.

6. Qi M, Williams JA, Chu H, Chen X, Wang JJ, Ding L, Akhirome E, Wen X, Lapierre LA, Goldenring JR, Spearman P. 2013. Rab11-FIP1C and Rab14 direct plasma membrane sorting and particle incorporation of the HIV-1 envelope glycoprotein complex. PLoS Pathog 9:e1003278.

7. Kirschman J, Qi M, Ding L, Hammonds J, Dienger-Stambaugh K, Wang JJ, Lapierre LA, Goldenring JR, Spearman P. 2017. HIV-1 Envelope Glycoprotein Trafficking through the Endosomal Recycling Compartment is Required for Particle Incorporation. J Virol doi:10.1128/JVI.01893-17.

8. Malbec M, Porrot F, Rua R, Horwitz J, Klein F, Halper-Stromberg A, Scheid JF,

9. Beliakova-Bethell N, Hezareh M, Wong JK, Strain MC, Lewinski MK, Richman Eden C, Mouquet H, Nussenzweig MC, Schwartz O. 2013. Broadly neutralizing antibodies that inhibit HIV-1 cell to cell transmission. J Exp Med 210:2813-21.

10. Chen P, Hubner W, Spinelli MA, Chen BK. 2007. Predominant mode of human immunodeficiency virus transfer between T cells is mediated by sustained Envdependent neutralization-resistant virological synapses. J Virol 81:12582-95. 2012. Cell-cell transmission enables HIV-1 to evade inhibition by potent CD4bs directed antibodies. PLoS Pathog 8:e1002634. 
384 12. Reh L, Magnus C, Schanz M, Weber J, Uhr T, Rusert P, Trkola A. 2015. Capacity of Broadly Neutralizing Antibodies to Inhibit HIV-1 Cell-Cell Transmission Is Strain- and Epitope-Dependent. PLoS Pathog 11:e1004966.

13. Checkley MA, Luttge BG, Freed EO. 2011. HIV-1 envelope glycoprotein biosynthesis, trafficking, and incorporation. J Mol Biol 410:582-608.

14. Hallenberger S, Bosch V, Angliker H, Shaw E, Klenk HD, Garten W. 1992. Inhibition of furin-mediated cleavage activation of HIV-1 glycoprotein gp160. Nature 360:358-61.

15. Stein BS, Engleman EG. 1990. Intracellular processing of the gp160 HIV-1

16. Miranda LR, Schaefer BC, Kupfer A, Hu Z, Franzusoff A. 2002. Cell surface expression of the HIV-1 envelope glycoproteins is directed from intracellular CTLA-4-containing regulated secretory granules. Proc Natl Acad Sci U S A 99:8031-6.

17. Byland R, Vance PJ, Hoxie JA, Marsh M. 2007. A conserved dileucine motif mediates clathrin and AP-2-dependent endocytosis of the HIV-1 envelope protein. Mol Biol Cell 18:414-25.

18. Rowell JF, Stanhope PE, Siliciano RF. 1995. Endocytosis of endogenously

20. Sauter MM, Pelchen-Matthews A, Bron R, Marsh M, LaBranche CC, Vance PJ, synthesized HIV-1 envelope protein. Mechanism and role in processing for association with class II MHC. J Immunol 155:473-88.

19. Wyss S, Berlioz-Torrent C, Boge M, Blot G, Honing S, Benarous R, Thali M. 2001. The highly conserved C-terminal dileucine motif in the cytosolic domain of the human immunodeficiency virus type 1 envelope glycoprotein is critical for its association with the AP-1 clathrin adaptor [correction of adapter]. J Virol 75:298292.

417 22. Boge M, Wyss S, Bonifacino JS, Thali M. 1998. A membrane-proximal tyrosinebased signal mediates internalization of the HIV-1 envelope glycoprotein via interaction with the AP-2 clathrin adaptor. J Biol Chem 273:15773-8. 
23. Ohno H, Aguilar RC, Fournier MC, Hennecke S, Cosson P, Bonifacino JS. 1997. Interaction of endocytic signals from the HIV-1 envelope glycoprotein complex with members of the adaptor medium chain family. Virology 238:305-15.

24. LaBranche CC, Sauter MM, Haggarty BS, Vance PJ, Romano J, Hart TK,

27. Del Portillo A, Tripodi J, Najfeld V, Wodarz D, Levy DN, Chen BK. 2011.

25. Iwami S, Takeuchi JS, Nakaoka S, Mammano F, Clavel F, Inaba H, Kobayashi T, Misawa N, Aihara K, Koyanagi Y, Sato K. 2015. Cell-to-cell infection by HIV contributes over half of virus infection. Elife 4.

28. Levy DN, Aldrovandi GM, Kutsch O, Shaw GM. 2004. Dynamics of HIV-1 recombination in its natural target cells. Proc Natl Acad Sci U S A 101:4204-9.

29. Gupta P, Balachandran R, Ho M, Enrico A, Rinaldo C. 1989. Cell-to-cell transmission of human immunodeficiency virus type 1 in the presence of azidothymidine and neutralizing antibody. J Virol 63:2361-5.

30. Sigal A, Kim JT, Balazs AB, Dekel E, Mayo A, Milo R, Baltimore D. 2011. Cell-tocell spread of HIV permits ongoing replication despite antiretroviral therapy. Nature 477:95-8.

31. Dale BM, McNerney GP, Thompson DL, Hubner W, de Los Reyes K, Chuang FY, Huser T, Chen BK. Cell-to-cell transfer of HIV-1 via virological synapses leads to endosomal virion maturation that activates viral membrane fusion. Cell Host Microbe 10:551-62.

32. Wang L, Eng ET, Law K, Gordon RE, Rice WJ, Chen BK. 2017. Visualization of HIV T Cell Virological Synapses and Virus-Containing Compartments by ThreeDimensional Correlative Light and Electron Microscopy. J Virol 91.

33. Wang L, Izadmehr S, Kamau E, Kong XP, Chen BK. 2019. Sequential trafficking of Env and Gag to HIV-1 T cell virological synapses revealed by live imaging. Retrovirology 16:2.

34. Hubner W, McNerney GP, Chen P, Dale BM, Gordon RE, Chuang FY, Li XD, Asmuth DM, Huser T, Chen BK. 2009. Quantitative 3D video microscopy of HIV transfer across T cell virological synapses. Science 323:1743-7. 
35. Ibraheem A, Campbell RE. 2010. Designs and applications of fluorescent protein-based biosensors. Curr Opin Chem Biol 14:30-6.

36. Nakane S, Iwamoto A, Matsuda Z. 2015. The V4 and V5 Variable Loops of HIV-1 Envelope Glycoprotein Are Tolerant to Insertion of Green Fluorescent Protein and Are Useful Targets for Labeling. J Biol Chem 290:15279-91.

37. Durham ND, Chen BK. 2015. HIV-1 Cell-Free and Cell-to-Cell Infections Are Differentially Regulated by Distinct Determinants in the Env gp41 Cytoplasmic Tail. J Virol 89:9324-37.

38. Bhakta SJ, Shang L, Prince JL, Claiborne DT, Hunter E. 2011. Mutagenesis of

39. Pedelacq JD, Cabantous S, Tran T, Terwilliger TC, Waldo GS. 2006. Engineering and characterization of a superfolder green fluorescent protein. Nat

41. Marsh M, Pelchen-Matthews A, Hoxie JA. 1997. Roles for endocytosis in

42. Bowers K, Pelchen-Matthews A, Honing S, Vance PJ, Creary L, Haggarty BS,

40. Hubner W, Chen P, Del Portillo A, Liu Y, Gordon RE, Chen BK. 2007. Sequence of human immunodeficiency virus type 1 (HIV-1) Gag localization and oligomerization monitored with live confocal imaging of a replication-competent, fluorescently tagged HIV-1. J Virol 81:12596-607. lentiviral replication. Trends Cell Biol 7:1-4.

Romano J, Ballensiefen W, Hoxie JA, Marsh M. 2000. The simian immunodeficiency virus envelope glycoprotein contains multiple signals that regulate its cell surface expression and endocytosis. Traffic 1:661-74.

43. Berlioz-Torrent C, Shacklett BL, Erdtmann L, Delamarre L, Bouchaert I, Sonigo P, Dokhelar MC, Benarous R. 1999. Interactions of the cytoplasmic domains of human and simian retroviral transmembrane proteins with components of the clathrin adaptor complexes modulate intracellular and cell surface expression of envelope glycoproteins. J Virol 73:1350-61.

44. Zhu P, Liu J, Bess J, Jr., Chertova E, Lifson JD, Grise H, Ofek GA, Taylor KA, Roux KH. 2006. Distribution and three-dimensional structure of AIDS virus envelope spikes. Nature 441:847-52.

45. Zhu P, Chertova E, Bess J, Jr., Lifson JD, Arthur LO, Liu J, Taylor KA, Roux KH. 2003. Electron tomography analysis of envelope glycoprotein trimers on HIV and simian immunodeficiency virus virions. Proc Natl Acad Sci U S A 100:15812-7.

46. Huse M, Lillemeier BF, Kuhns MS, Chen DS, Davis MM. 2006. T cells use two directionally distinct pathways for cytokine secretion. Nat Immunol 7:247-55. 
494 47. Jolly C, Sattentau QJ. 2007. Regulated secretion from CD4+ T cells. Trends Immunol 28:474-81.

496 48. Finetti F, Onnis A, Baldari CT. 2015. Regulation of vesicular traffic at the T cell immune synapse: lessons from the primary cilium. Traffic 16:241-9.

49. Jouvenet N, Bieniasz PD, Simon SM. 2008. Imaging the biogenesis of individual HIV-1 virions in live cells. Nature 454:236-40.

500 50. Tedbury PR, Ablan SD, Freed EO. 2013. Global rescue of defects in HIV-1 envelope glycoprotein incorporation: implications for matrix structure. PLoS Pathog 9:e1003739.

503

51. Buttler CA, Pezeshkian N, Fernandez MV, Aaron J, Norman S, Freed EO, van Engelenburg SB. 2018. Single molecule fate of HIV-1 envelope reveals latestage viral lattice incorporation. Nat Commun 9:1861.

52. Day JR, Munk C, Guatelli JC. 2004. The membrane-proximal tyrosine-based sorting signal of human immunodeficiency virus type $1 \mathrm{gp} 41$ is required for

53. von Bredow B, Arias JF, Heyer LN, Gardner MR, Farzan M, Rakasz EG, Evans DT. 2015. Envelope Glycoprotein Internalization Protects Human and Simian Immunodeficiency Virus-Infected Cells from Antibody-Dependent Cell-Mediated Cytotoxicity. J Virol 89:10648-55.

514

515

54. Egan MA, Carruth LM, Rowell JF, Yu X, Siliciano RF. 1996. Human immunodeficiency virus type 1 envelope protein endocytosis mediated by a highly conserved intrinsic internalization signal in the cytoplasmic domain of gp41 is suppressed in the presence of the Pr55gag precursor protein. J Virol 70:654756.

518 55. Li H, Zony C, Chen P, Chen BK. 2017. Reduced Potency and Incomplete

521 56. Adachi A, Gendelman HE, Koenig S, Folks T, Willey R, Rabson A, Martin MA. 1986. Production of acquired immunodeficiency syndrome-associated retrovirus

523 in human and nonhuman cells transfected with an infectious molecular clone. $J$ Virol 59:284-91. 
528 into V4 or V5 domains of Env. (A) sfGFP is inserted into HIV-1(NL4-3) in V4 or V5. (B) Virus

529 production by fluorescent Env HIV constructs following transfection of 293T cells. (C) Cell-free

530 virus infectivity was tested by infection of indicator cell line, Tzm-bl. Tzm-bl cells were infected

531 with supernatants with same amount of p24. (D) Western blot analysis of lysates of transfected

532 293T cells or of virus particles harvested from transfected cell supernatants and purified

533 through a $20 \%$ sucrose cushion. Blots were probed with anti-gp120 or anti-GFP antibody. Viral

534 supernatants and cell lysates were collected at $48 \mathrm{~h}$ post transfection. (E) Infection of Jurkat

535 cells or MT4 cells with virus was assessed on day 3 after infection. (F) Infection of MT4 cells

536 initiated by co-culture with HIV-nucleofected Jurkat T cells. FACS analysis was used to monitor

537 the fraction of MT4 cells infected over time. (G) Infection of Jurkat cells initiated by co-culture

538 with HIV-nucleofected Jurkat T cells. FACS analysis was used to monitor the fraction of Jurkat

539 cells infected over time.

540 Figure 2. Fluorescence microscopy showing cellular distribution of sfGFP-tagged Env in Jurkat

541 cells. (A-D) Confocal fluorescence microscopy imaging of Jurkat cells transfected with HIV Env

542 V4.2-Gag-iCherry were fixed and stained with anti-Env mAb 2 G12 (Magenta). A, V4.2 sfGFP Env

543 localization, B, 2 G12 Env immunostaining, C, Merged image, D, merged image with bright field

544 overlay. (E) Graph shows the fluorescence intensity of Env and 2 G12 staining traced along the

545 line indicated in (D). (F-I) Super resolution structured illumination imaging of Jurkat cell

546 transfected with V4.2-Gag-iCherry were stained with cell mask Deep Red. F, Cherry-Gag; G,

547 sfGFP-Env, H, Cell Mask; I, Merged image. (J) Graph shows the fluorescence intensity of Gag, 
548 Env and plasma membrane along the line as indicated in (I). (K-M) Cell surface Env was stained

549 with anti-GFP followed by secondary antibody while cells were alive at $4^{\circ} \mathrm{C}$. The cells were then

550 imaged for surface anti-GFP Env staining, $\mathrm{K}$, single confocal plane; $L$, single plans merged with

551 bright field; M, Z-projection of stack. (N) Confocal z stacks were acquired at 10-min intervals

552 from $6 \mathrm{~h}$ post transfection for $20 \mathrm{~h}$. Series of images show montage of fluorescence expression

553 illustrating changes in the fluorescence pattern of Env-V4.2-sfGFP. (0) Env-sfGFP fluorescence is

554 concentrated where two target cells make contact with a donor Jurkat cell. (P) is a bright field

555 snap of (O). (Q) shows Env accumulation at VS area between an infected primary CD4 T cell and

556 a target primary CD4 T cell. Bar: $5 \mu \mathrm{m}$.

557 Figure 3. Cell-to-cell HIV-1 transfer assays using dual fluorescent construct of V4/V5-Gag-

558 iCherry. (A) Dual fluorescent HIV-1 constructs produce viral particles in 293T cells as measured

559 by p24 ELISA. (B) Infectivity of these dual fluorescent HIV-1 constructs using Tzm-bl assay shows

560 infectivity of single fluorescent Env constructs and low infectivity of viruses carrying chimeric

561 Gag-iCherry or Gag-iGFP. (C) Dual fluorescent constructs HIV-1 V4.2-Gag-iCherry participates in

562 cell-to-cell transfer of HIV from Jurkat to primary CD4 T cells. Flow cytometry measures

563 transfer of Gag-iCherry and Env V4.2-sfGFP signal following cell-cell co-culture, and the transfer

564 is sensitive to CD4 antibody leu3a. (D) Cell-to-cell HIV-1 transfer of Gag and Env measured with

565 indicated fluorescent HIV-1 constructs. (E) HIV-1 virological synapses between HIV V4.2-Gag-

566 iCherry transfected Jurkat cells and primary CD4 T cells. Primary CD4 cells from healthy human

567 blood were co-cultured with transfected donor cells for $3 \mathrm{~h}$. upper panel: A typical synaptic

568 button with both Gag and Env was shown between a donor Jurkat cell and a target cell. Lower

569 panel: one donor cell nucleofected with V4.2-Gag-iCherry formed two virological synapses: the 
570 lower synapse shows both Env and Gag concentrated at the cell-cell contact site, while the

571 upper synapse shows Gag accumulation without Env accumulation. (F) Analysis of Env and Gag

572 colocalization at virological synapses. Samples fixed at 1 hour post co-culture and 3 hours post

573 co-culture were compared. Virological synapses defined by Gag at the site of cell-cell contact

574 were counted if Env was visible at cell contact site. (G) Transfer of both Gag and Env into target

575 cells. Co-cultured cells were fixed and observed by confocal microscopy. Inset shows partial

576 colocalization of transferred Gag and Env. Green, red and yellow arrowheads show Env only,

577 Gag only transfer or co-transfer of both Gag and Env. Bar: $5 \mu \mathrm{m}$.

578 Figure 4. Pulse-chase labeling of cell-surface Env shows that recycled Env is targeted to

579 virological synapse. (A) Live cell surface staining of V4.2-Gag-iCherry: nucleofected Jurkat cells

580 stained with anti-GFP antibody at $4^{\circ} \mathrm{C}$. (B) Pulse-chase of surface Env to determine time

581 required for endocytosis: cells with surface stained Env were moved from $4^{\circ} \mathrm{C}$ to $37^{\circ} \mathrm{C}$ and kept

582 for indicated time. The cells were fixed after incubation at $37^{\circ} \mathrm{C}$ and imaged. (C) The stained

583 cells in (A) were immediately co-cultured with primary CD4 target cells for 30 min at $37^{\circ} \mathrm{C}$ and

584 fixed for imaging. (D) The stained cells in (A) were put in $37^{\circ} \mathrm{C}$ for $30 \mathrm{~min}$ first, then co-cultured

585 with primary CD4 target cells for another $30 \mathrm{~min}$ at $37{ }^{\circ} \mathrm{C}$ and fixed for imaging. Arrowheads

586 show virological synapses. Bar: $6 \mu \mathrm{m}$.

588 Figure 5. Rapid Env fluorescence recovery after photobleaching was observed at the VS. (A1)

589 Before photobleaching a virological synapse with both Gag and Env could be observed between

590 a donor cell and a target cell. A region covering part of the synaptic button is bleached as 
591 shown in the white square. After photobleaching, obvious fluorescent recovery was observed in

592 Env, but not in Gag. ROls were selected on bleached synapse or an unbleached area as shown in

593 closed yellow region. A fluorescence intensity curve describing the fluorescence recovery is

594 shown (left). Four additional representative cells repeating experiments with wild type V4.2-

595 Gag-iCherry are displayed in (A2-A5). (B) shows the immobile fraction of each FRAP experiment.

596 (C) shows the half recovery time of A1-A5. Bar: $3 \mu \mathrm{m}$.

597 Figure 6. Env fluorescence after photobleaching does not recover when examining Y712A

598 mutants of V4.2-sfGFP in FRAP. (A) Jurkat cells nucleofected with wild type Env-V4.2-sfGFP or

599 Env-V4.2-Y712A-sfGFP were co-cultured with primary CD4 cells for 3 hours. Env transfer to

600 primary CD4 cells were determined by Flow cytometry. (B) Jurkat cells nucleofected with wild

601 type, Env-V4.2-sfGFP, or Env-V4.2-Y712A-sfGFP were co-cultured with activated primary CD4

602 cells to monitor productive infection in target cells. Samples were collected on day 1, 3, 5, 7 to

603 determine the portion of primary CD4 cells with fluorescent Env. (C) Jurkat cells nucleofected

604 with wild type, Env-V4.2-sfGFP, or Env-V4.2-Y712A-sfGFP were co-cultured with MT4 cells for

605 days to monitor productive infection in target cells. Samples were collected on day 1, 3, 5, 7 to

606 determine the portion of MT4 cells with fluorescent Env. (D) Fluorescence recovery after

607 photobleaching (FRAP) of Env and Gag virological synapse with V4.2-712A-Gag-iCherry. Before

608 photobleaching a virological synapse, both Gag and Env are concentrated at the junction

609 between a donor cell and a target cell. A region of interest covering part of the synaptic button

610 was bleached as shown in white square. ROls were selected on bleached synapse (ROI-1) or an

611 unbleached area (ROI-2) as shown in closed yellow region. Recovery curves of five individual 
612 experiments are displayed in (D1-D5). (E) shows the immobile fraction of each FRAP

613 experiment. Bar: $5 \mu \mathrm{m}$.

614 Figure 7. Model of Env trafficking pathways that support Env accumulation at the VS. (1) Env

615 is transported to the cell surface following synthesis through the ER/Golgi pathways. (2)

616 Clathrin-mediated endocytosis is initiated by recognition of the Env cytoplasmic tail by adapter

617 protein complex, AP-2, which recognizes the membrane proximal tyrosine motif in Env. (3)

618 Following internalization Env is recycled back to the cell surface, selectively trafficking to the VS

619 where it can be incorporated into nascent virus particles. (4) Env at the VS continues to recycle

620 while Gag does not exchange.

626 METHODS

627 KEY RESOURCES TABLE

\begin{tabular}{|l|l|l|}
\hline REAGENT or RESOURCE & SOURCE & IDENTIFIER \\
\hline Antibodies & \multicolumn{2}{l|}{} \\
\hline anti-p24 capture antibody & Aalto Bio Reagents & Cat\# D7320 \\
\hline Alkaline phosphatase conjugated mouse anti-HIV p24 & Aalto Bio Reagents & Cat\# BC1071-AP \\
\hline anti-GFP rabbit serum & Invitrogen & Cat\# A6455 \\
\hline anti-HIV Immune Globulin (HIVIG) & AIDS reagents & Cat\# 3957 \\
\hline Anti-rabbit horseradish peroxidase conjugated 2' Ab & Jackson Immunoresearch & Cat\#111-035-003 \\
\hline Anti-human horseradish peroxidase conjugated 2' Ab & Jackson Immunoresearch & Cat\#709-035-149 \\
\hline
\end{tabular}




\begin{tabular}{|c|c|c|}
\hline Leu3a (HIV-blocking anti-CD4 antibody) & BD Biosciences & Cat\#340853 \\
\hline $2 \mathrm{G} 12$ & AIDS reagent & Cat\# 1476 \\
\hline \multicolumn{3}{|l|}{ Bacterial and Virus Strains } \\
\hline NL4-3 & $(56)$ & $\mathrm{N} / \mathrm{A}$ \\
\hline Gag-iGFP & $(40)$ & $\mathrm{N} / \mathrm{A}$ \\
\hline Gag-iCherry & $(40)$ & $\mathrm{N} / \mathrm{A}$ \\
\hline HIV-1 Env-V4.1-sfGFP & This paper & $\mathrm{N} / \mathrm{A}$ \\
\hline HIV-1 Env-V4.2-sfGFP & This paper & $\mathrm{N} / \mathrm{A}$ \\
\hline HIV-1 Env-V5.2-sfGFP & This paper & $\mathrm{N} / \mathrm{A}$ \\
\hline HIV-1 Env-V5.3-sfGFP & This paper & $\mathrm{N} / \mathrm{A}$ \\
\hline HIV-1 Env V4.1 sfGFP-Gag-iCherry & This paper & $\mathrm{N} / \mathrm{A}$ \\
\hline HIV-1 Env V4.2 sfGFP-Gag-iCherry & This paper & $\mathrm{N} / \mathrm{A}$ \\
\hline HIV-1 Env V5.2 sfGFP-Gag-iCherry & This paper & $\mathrm{N} / \mathrm{A}$ \\
\hline NL-sfGI & $(26)$ & $\mathrm{N} / \mathrm{A}$ \\
\hline HIV-1 Env-V4.2-712A-sfGFP & This paper & $\mathrm{N} / \mathrm{A}$ \\
\hline HIV-1 V4.2-Y712A-Gag-iCherry & This paper & $\mathrm{N} / \mathrm{A}$ \\
\hline \multicolumn{3}{|l|}{ Biological Samples } \\
\hline Human: PBMC (from peripheral blood) & New York Blood Center & $\mathrm{N} / \mathrm{A}$ \\
\hline Human: primary CD4 T cells (from peripheral blood) & New York Blood Center & $\mathrm{N} / \mathrm{A}$ \\
\hline \multicolumn{3}{|l|}{ Chemicals, Peptides, and Recombinant Proteins } \\
\hline Dulbecco's Modified Eagle Medium (DMEM) & Gibco & $12491-015$ \\
\hline RPMI 1640 & Sigma-Aldrich & R8758 \\
\hline Penicillin-Streptomycin $(10,000 \mathrm{U} / \mathrm{mL})$ & Sigma-Aldrich & 15140122 \\
\hline Fetal bovine serum (FBS) & Gibco & 10082147 \\
\hline IL-2 & Miltenyi & $130-097-746$ \\
\hline $\mathrm{PHA}$ & MilliporeSigma & 431784 \\
\hline Polyjet transfection reagent & Signagen & SL100688 \\
\hline Phosphate buffered saline (PBS) & Gibco & 13151014 \\
\hline
\end{tabular}




\begin{tabular}{|c|c|c|}
\hline TBST & Lab self-made & $\mathrm{N} / \mathrm{A}$ \\
\hline Empigen & Millipore & 324690 \\
\hline Sapphire Substrate & Invitrogen & T2210 \\
\hline RIPA buffer & Alfa Aesar & AAJ62885AE \\
\hline Protease inhibitor cocktail & Abcam & Ab201119 \\
\hline Non-fat dry milk & Lab Scientific & $732-291-1940$ \\
\hline Ficoll & Cytiva & 45001750 \\
\hline Poly-L-lysine & Ted Pella, INC & 18026 \\
\hline Triton X-100 & Sigma & $9002-93-1$ \\
\hline fibronectin & Corning & CB40008 \\
\hline DAPI mounting media & Vectashield & $\mathrm{H}-1200$ \\
\hline \multicolumn{3}{|l|}{ Critical Commercial Assays } \\
\hline CD4 T cell isolation kit II & Miltenyi Biotec & $130-096-533$ \\
\hline Luciferase Assay System & Promega & E1501 \\
\hline $\begin{array}{l}\text { Super Signal West Femto Maximum Sensitivity } \\
\text { Substrate }\end{array}$ & Thermo Scientific & 34095 \\
\hline \multicolumn{3}{|l|}{ Experimental Models: Cell Lines } \\
\hline Human: Jurkat E6-1 cells & Arthur Weiss, ARRP & $\mathrm{N} / \mathrm{A}$ \\
\hline Human: MT4 cells & Douglass Richman, ARRP & $\mathrm{N} / \mathrm{A}$ \\
\hline Human: 293T cells & ATCC & CRL-3216 \\
\hline \multicolumn{3}{|l|}{ Oligonucleotides } \\
\hline $\begin{array}{l}\text { P1SFGFP : AGCGGCGGAGGCGGAATGGTGAGCAA } \\
\text { GGGCGAGGAGCT }\end{array}$ & Eurofins genomics & $\mathrm{N} / \mathrm{A}$ \\
\hline $\begin{array}{l}\text { P2SFGFP : GCTGCCTCCACCTCCCTTGTACAGCT } \\
\text { CGTCCATGCCG }\end{array}$ & Eurofins genomics & $\mathrm{N} / \mathrm{A}$ \\
\hline $\begin{array}{l}\text { P3V4 . } 1 \text { : CTTGCTCACCATTCCGCCTCCGCCGCT } \\
\text { CССTTCAGTACTCCAАGTAСTATT }\end{array}$ & Eurofins genomics & $\mathrm{N} / \mathrm{A}$ \\
\hline $\begin{array}{l}\text { P4V4 . } 1 \text { : GGACGAGCTGTACAAGGGAGGTGGAGG } \\
\text { CAGCTCAAATAACACTGAAGGAagtgacac }\end{array}$ & Eurofins genomics & $\mathrm{N} / \mathrm{A}$ \\
\hline $\begin{array}{l}\text { P3V4 . } 2 \text { : СTTGCTCACCATTCCGCCTCCGCCGCT } \\
\text { ATTTGACCСTTAATACTCCAAG }\end{array}$ & Eurofins genomics & $\mathrm{N} / \mathrm{A}$ \\
\hline
\end{tabular}




\begin{tabular}{|c|c|c|}
\hline $\begin{array}{l}\text { P4V4 . } 2 \text { : GGACGAGCTGTACAAGGGAGGTGGAGG } \\
\text { CAGCAACACTGAAGGAAGTGACacaatc }\end{array}$ & Eurofins genomics & $\mathrm{N} / \mathrm{A}$ \\
\hline $\begin{array}{l}\text { P3V5 . } 2 \text { : CTTGCTCACCATTCCGCCTCCGCCGCT } \\
\text { GTTGTTATTACCACCATCTCTTGT }\end{array}$ & Eurofins genomics & $\mathrm{N} / \mathrm{A}$ \\
\hline $\begin{array}{l}\text { P4V5 . } 2 \text { : GGACGAGCTGTACAAGGGAGGTGGAGG } \\
\text { CAGCAATGGGTCCGAGATCTTC }\end{array}$ & Eurofins genomics & $\mathrm{N} / \mathrm{A}$ \\
\hline $\begin{array}{l}\text { P3V5 . } 3 \text { : CTTGCTCACCATTCCGCCTCCGCCGCT } \\
\text { ATTGTTGTTATTACCACCATCTCTtg }\end{array}$ & Eurofins genomics & $\mathrm{N} / \mathrm{A}$ \\
\hline $\begin{array}{l}\text { P4V5 . } 3 \text { : GGACGAGCTGTACAAGGGAGGTGGAGG } \\
\text { CAGCGGTCCGAGATCTTCAGA }\end{array}$ & Eurofins genomics & $\mathrm{N} / \mathrm{A}$ \\
\hline $\begin{array}{l}\text { P5NheI : aTAGCTAGCAAATTAAGAGAACAATTT } \\
\text { GGA }\end{array}$ & Eurofins genomics & $\mathrm{N} / \mathrm{A}$ \\
\hline $\begin{array}{l}\text { P6BamHI : taaGGATCCGTTCACTAATCGAATGG } \\
\text { ATCT }\end{array}$ & Eurofins genomics & $\mathrm{N} / \mathrm{A}$ \\
\hline \multicolumn{3}{|l|}{ Software and Algorithms } \\
\hline Prism & Graphpad software & Version 8 \\
\hline Volocity & Perkin Elmer & Volocity 6.3 \\
\hline Image J & $\mathrm{NIH}$ & Imagej.net \\
\hline Metamorph & Molecular Devices & $\begin{array}{l}\text { Moleculardevices } \\
\text {.com }\end{array}$ \\
\hline Imaris & bitmap & Imaris.oxinst.com \\
\hline FlowJo & BD Biosciences & www.flowjo.com \\
\hline SoftWoRx & Amersham & Version 7.0.0 \\
\hline \multicolumn{3}{|l|}{ Other } \\
\hline$\mu$-Slide VI ${ }^{0.4}$ & ibidi & Cat\#80606 \\
\hline
\end{tabular}

629 CONTACT FOR REAGENT AND RESOURCE SHARING

630 Further information and requests for resources and reagents should be directed to and will be

631 fulfilled by the Lead Contact, Benjamin K. Chen (benjamin.chen@mssm.edu).

632 Distribution of fluorescent Env HIV lab strains will require signing Material Transfer Agreement

633 (MTA) in accordance with policies of Mount Sinai Medical Center. 


\section{Cell lines}

636 The CD4 ${ }^{+}$T-cell line Jurkat CE6.1 (ATCC) and CD4 ${ }^{+}$T-cell line MT4 were maintained in RPMI 6371640 with $100 \mathrm{U} / \mathrm{ml}$ penicillin, $100 \mathrm{U} / \mathrm{ml}$ streptomycin and 10\% fetal bovine serum (FBS). Cells 638 were maintained at concentrations of less than $10^{6} / \mathrm{ml}$. Primary CD4 ${ }^{+} \mathrm{T}$ cells were obtained from

639 human peripheral blood from deidentified HIV-negative blood donors, through the New York 640 Blood Center and CD4+ cells isolated by negative selection with a Miltenyi CD4 T cell isolation 641 kit II (Miltenyi Biotec). Cell-free virus was produced by transfection of 293T cells in $10 \mathrm{~cm}$ plates 642 using polyjet (Signagen). Media was exchanged 16h post transfection and virus supernatants 643 were harvested $48 \mathrm{~h}$ post transfection.

\section{Human primary CD4 T cells}

645 Human primary CD4 ${ }^{+} \mathrm{T}$ cells are obtained from peripheral blood with CD4 $\mathrm{T}$ cell isolation kit II 646 (Miltenyi Biotec). Unactivated $\mathrm{CD}^{+} \mathrm{T}$ cells were maintained in complete RPMl medium 647 containing $50 \mathrm{U} / \mathrm{ml}$ interleukin 2 (IL-2; ARP). Activated primary CD4 ${ }^{+}$cells were induced by co648 culture with radiated PBMC feeder cells plus $100 \mathrm{U} / \mathrm{ml} \mathrm{IL-2}$ and $4 \mu \mathrm{g} / \mathrm{ml} \mathrm{PHA} \mathrm{for} 3$ days.

\section{Viruses}

650 HIV Gag-iGFP and HIV Gag-iCherry are full-length molecular clones of HIV based on NL4-3

651 (Adachi et al.) previously designed to carry the green fluorescent protein (GFP) or mCherry 652 protein inserted between the Gag MA and CA domains (40). HIV constructs with fluorescent

653 Env were constructed by inserting Superfolder green fluorescent protein (sfGFP) internally into 654 the Env V4 or V5 domains, designated HIV Env- HIV V4.1-sfGFP, HIV Env-V4.2-sfGFP, HIV 655 Env-V5.2-sfGFP or HIV Env-V5.3-sfGFP. The superfolder GFP is introduced by 2-step PCR 656 with the primers shown in key resource table. These fluorescent Env genes are also inserted 
657 into the context of HIV Gag-iCherry to yield constructs carrying Gag-iCherry and Env-sfGFP in 658 cis. Y712A mutant was introduced by site mutation primer shown in key resource table.

\section{METHOD DETAILS}

\section{1 p24 ELISA}

662 Costar 3922 flat-bottomed, high binding plates were coated with anti-p24 capture antibody 663 overnight (Aalto D7320; 1:200 in 0.1M NaHCO3). Plate was washed twice with 1x TBST and 664 blocked with $2 \%$ nonfat dry milk (Lab Scientific) for $1 \mathrm{~h}$ then washed in TBST. HIV supernatants 665 treated with 1\% Empigen (1:100 and 1:1,000 in DMEM) along with titration of p24 standard are 666 added to wells and incubated at room temperature for 2 hours, then washed $4 \mathrm{x}$ with TBST. 667 Alkaline phosphatase conjugated mouse anti-HIV p24 (CLINIQA) was added (1:8,000 in TBST $66820 \%$ sheep serum) and incubated for $1 \mathrm{hr}$ followed by 6 TBST washes. $50 \mu \mathrm{l}$ of Sapphire

669 Substrate (Tropix) was added to each well and incubated for 20 minutes. Luminescence was 670 quantitated on Fluo Star Optima plate reader and sample values calculated based on nonlinear 671 regression of standard curve using Prism software (Graphpad Inc.).

\section{Western Blot Analysis}

673 Cells or virus were lysed with RIPA buffer and protease inhibitor cocktail (Sigma). Protein

674 loaded from viral lysates were normalized to p24 antigen content. Lysate equivalent of 675 approximately $2 \times 10^{5}$ cells per well were run on NuPage $4-12 \%$ Bis-Tris Gel (Novex) and 676 transferred to Amersham Hybond-P PVDF membranes (GE Healthcare). Membranes were 677 blocked with $2 \%$ nonfat dry milk (Lab Scientific), then probed with rabbit anti-GFP serum $678(1: 5,000)$ or human anti-HIV serum $(1: 10,000)$ primary antibodies followed by anti-rabbit 
679 (Jackson Immunoresearch) or anti-human horseradish peroxidase (Jackson Immunoresearch) 680 conjugated secondary antibody. Detection of band is using Super Signal West Femto Maximum 681 Sensitivity Substrate (Thermo Scientific).

\section{TZM-bl assay}

683 Cell-free viruses were produced in 293 T cells. TZM-bl cells were plated at $2 \times 10^{4}$ cells/well in 96684 well plates and incubated at $37^{\circ} \mathrm{C}$ with indicated viruses. Media was replaced after $24 \mathrm{~h}$ of 685 infection and incubated for another $24 \mathrm{~h}$. At $48 \mathrm{~h}$ post infection, Media was aspirated followed by 686 lysis in Luciferase Cell Culture Lysis Reagent (Promega). $20 \mu$ l of each sample was read on Fluo 687 Star Optima plate reader with injection of $50 \mu$ of Luciferase Assay Reagent (Promega).

\section{Cell-to-cell transfer assay}

689 HIV-1 proviral constructs were transduced into Jurkat cells (donor cells) using Amaxa 690 nucleofection as previously described (Amaxa Biosystems). In brief, $5 \mu \mathrm{g}$ of endotoxin-free HIV6911 proviral plasmids was nucleofected into $6 \times 106$ Jurkat cells using Cell Line Nucleofector kit V, 692 program S-18. Twenty hours after nucleofection, viable Jurkat cells were purified by 693 centrifugation on a Ficoll-Hypaque density gradient, washed with complete buffer, and 694 recovered at $37^{\circ} \mathrm{C}$ for co-culture. Unactivated primary CD4+ T cells (target cells) were cultured 695 overnight in complete RPMI medium containing $50 \mathrm{U} / \mathrm{ml}$ IL-2. Donor and target cells were mixed 696 at a ratio of approximately $1: 1$ and cocultured at $37^{\circ} \mathrm{C}$ for $3 \mathrm{~h}$ before they were treated with 697 trypsin and fixed. Where inhibitor Leu3a, an HIV-blocking anti-CD4 antibody (BD Biosciences) 698 was used, donor and target cells were preincubated separately with equal volumes of inhibitor 699 for $30 \mathrm{~min}$ at $37^{\circ} \mathrm{C}$ before mixing. 
701 Transfected Jurkat cells (donor cells) were mixed with primary CD4 cells (target cells) in round

702 bottom 96-well-plates for 3-4 hours as previously described. Trim the pipette tips to reduce the

703 shearing to cells. Co-cultured donor and target cells were carefully transferred without

704 disturbance onto poly-lysine treated coverslips. The cells were plated onto the poly-L-lysine

705 treated coverslip for $30 \mathrm{~min}$ in $37^{\circ} \mathrm{C}$ incubator. Media was removed and cells fixed with $4 \%$ PFA

706 for 10 min at room temperature, washed twice with PBS, and mounted with anti-fade mounting

707 medium with DAPI (Vectashield, Co\#: H-1200, Vector Laboratories). For intracellular staining of

708 Env with 2G12, transfected Jurkat cells were plated onto poly-L-lysine treated cover glass and

709 allowed to attach for $30 \mathrm{~min}$ at $37^{\circ} \mathrm{C}$. The cells were permeabilized with PBS containing $0.1 \%$

710 triton X-100 and 2\% FBS for 5 minutes. Next the cells were stained with 2 G12 (1:200) for 1 hour

711 followed by secondary antibody for 45 minutes. After washing, the samples were sealed in

712 mounting media and ready to observe. For surface staining of Env, the cells were directly

713 stained at $4^{\circ} \mathrm{C}$ with anti-GFP antibody (1:500) diluted in PBS with $2 \%$ FBS for 45 min, followed

714 by a secondary antibody for $30 \mathrm{~min}$, and then washed and fixed in 4\% PFA or kept alive for live

715 cell pulse-chase experiments.

\section{Confocal and live imaging}

717 Confocal imaging was carried out on an inverted Leica SP5 DMI laser scanning confocal

718 microscope, using a 63× objective and analyzed using Volocity (PerkinElmer) or ImageJ (NIH)

719 software. Live imaging was carried out in a sealed, gas permeable microchamber slides (Ibidi

720 Biosciences). Donor cells were mixed with target cells at a ratio of 1:2 and were loaded onto the

721 micro-chamber pre-coated with $150 \mathrm{~g} / \mathrm{ml}$ fibronectin to provide the cells with a two- dimensional

722 substrate for attachment and migration. The chamber was placed on a Zeiss AxioObserver Z1

723 inverted microscope mounted with Yokogawa CSU-X1 spinning disk scan head. Dual

724 Hamamatsu EM-CCD C9100 digital cameras enable simultaneous imaging of up to two 
725 fluorescent channels. Phase contrast imaging and confocal green (for sfGFP) and red (for

726 mCherry) fluorescence were acquired in a multitrack configuration to avoid cross-talk between

727 fluorescence channels. Images were recorded at different time intervals continuously as

728 indicated in results. Confocal images and Quicktime movies were generated from laser-

729 scanning confocal microscope file data using using Metamorph software (Molecular Devices)

730 and Imaris (bitmap) software.

\section{Fluorescence Recovery after Photobleaching (FRAP)}

732 FRAP was performed on two systems: Zeiss LSM880 and Leica SP5 DMI. Zeiss LSM880

733 Airyscan microscope equipped with a $63 \mathrm{X}$ oil-immersion objective (NA 1.4) using the $561 \mathrm{~nm}$

734 and $488 \mathrm{~nm}$ laser lines. The system is adjusted to proper humidity, $5 \% \mathrm{CO} 2$ and $37^{\circ} \mathrm{C}$. The

735 FRAP experiment on LSM880 used a 4-minute protocol: pre-bleach for $3 \mathrm{sec}$, bleach for 1 sec

736 at $60 \%$ laser power and recovery of fluorescence was captured for the last of the 4 minutes. On

737 Leica SP5 DMI, we used a 60X oil-immersion objective (NA1.4) with $561 \mathrm{~nm}$ and $488 \mathrm{~nm}$ laser

738 lines. There is an inherent three-step capturing protocol from the system. After 1s bleaching, the

739 first 100 frames were captured continuously; the second 50 frames were at 1 s/frame and the

740 last 50 frames at 5s/frame. A rectangular zone covering about half of the virological synapse

741 was bleached, leaving the other half as unbleached area control and localization reference. In

742 one case, where the virological synapse was too small to bleach a fraction of it, a nearby area

743 was selected as unbleached area control. FRAP curve of the bleached virological synapse was

744 determined from ROI rigidly covering the synapse button. A normal bleaching curve was

745 determined from a different area covering most of the cytoplasm of the same cell and used for

746 normalization of values. Fluorescence intensity over time was plotted using GraphPad Prism

747 software, and the data were fitted to a one-phase exponential association function to calculate

748 recovery half-times and immobile fractions. 


\section{Super-resolution optical microscopy of HIV-infected T cells}

750 3D structured illumination microscopy of fixed T cells cells was performed with a commercial

751 Deltavision OMXv4.0 BLAZE microscope (GE Healthcare, Amersham, UK) using a 60x, 1.42

752 NA oil immersion PlanApoN objective lens (Olympus, Japan) and sCMOS cameras. Env tagged

753 with sfGFP was excited at $488 \mathrm{~nm}$ and the emission recorded at 504-552 nm. Gag tagged with

754 mCherry was excited at $546 \mathrm{~nm}$ and the emission recorded at $600-650 \mathrm{~nm}$. The plasma

755 membrane was stained with CellMask Deep Red, excited at $649 \mathrm{~nm}$ and the emission recorded

756 at $660-670 \mathrm{~nm}$. The nucleus was stained with DAPI, excited at $405 \mathrm{~nm}$ and the emission

757 recorded at $450-470 \mathrm{~nm}$. A sequence of 15 images for each axial plane, obtained at three

758 different angles with five phases each, was acquired. Multiple axial planes encompassing the

759 entire cell from top to bottom were recorded at a separation of the individual axial planes of 125

$760 \mathrm{~nm}$. Super-resolved fluorescent images were reconstructed with the corresponding recorded

761 optical transfer function (OTF) in the SoftWoRx 7.0.0 software (GE Healthcare, Amersham, UK)

762 at a Wiener filter setting of 0.006.

\section{DATA AND SOFTWARE AVAILABILITY}

764 Primary imaging data are available upon request. 
bioRxiv preprint doi: https://doi.org/10.1101/2020.12.08.417188; this version posted December 10, 2020. The copyright holder for this preprint (which was not certified by peer review) is the author/funder. All rights reserved. No reuse allowed without permission.

\section{Figure 1}

A

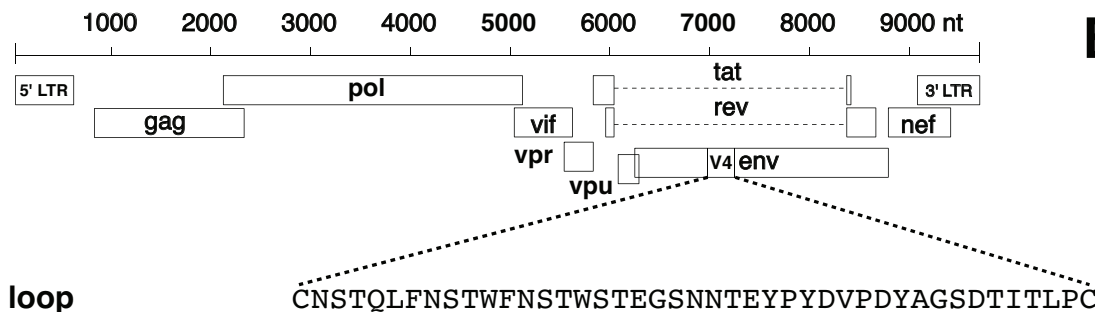

NL4-3 V4 loop CNSTQLFNSTWFNSTWSTEGSNNTEYPYDVPDYAGSDTITLPC

\section{Insertion in Env-V4.1-sfGFP} STWSTEGSGGGG superfolder GFP GGGGSSNNTEGS

Insertion in Env-V4.2-sfGFP STWSTEGSNSGGG superfolder GFP GGGGSNTEGS

Insertion in Env-V5.2-sfGFP TRDGGNNNSGGGG superfolder GFP GGGGSNSEIFRPG Insertion in Env-V5.3-sfGFP TRDGGNNNNSGGG superfolder GFPGGGGSSEIFRPG

D

Cell lysates

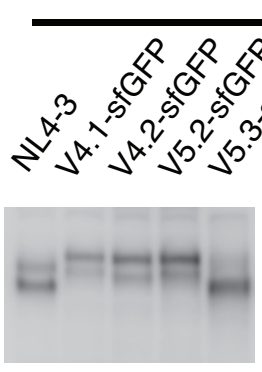

anti-gp120

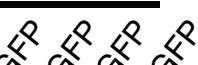

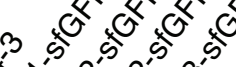

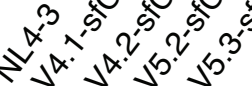

Purified viral particles

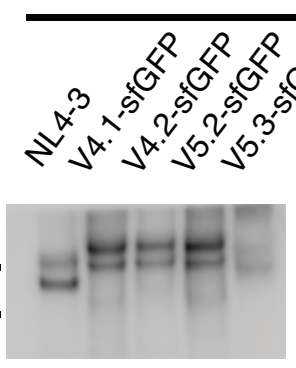

anti-gp120
B

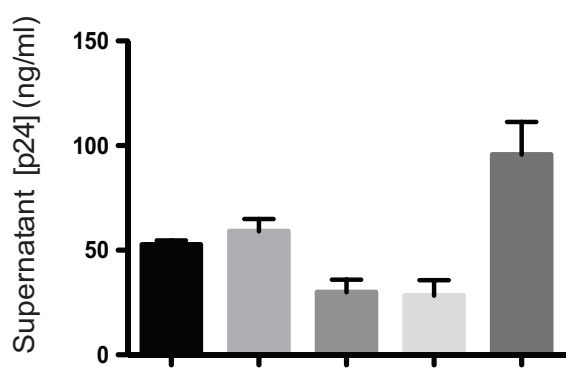

C
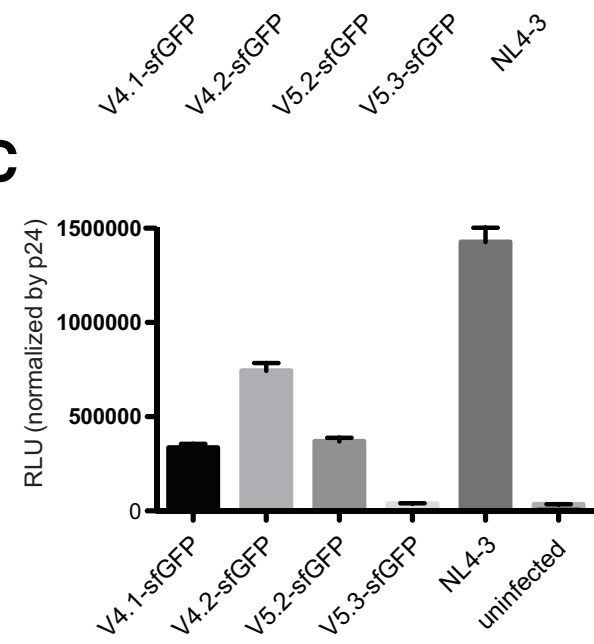

E

anti-GFP
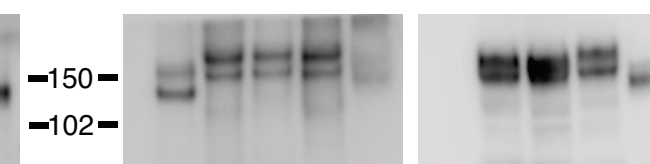

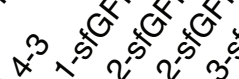

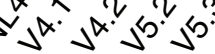

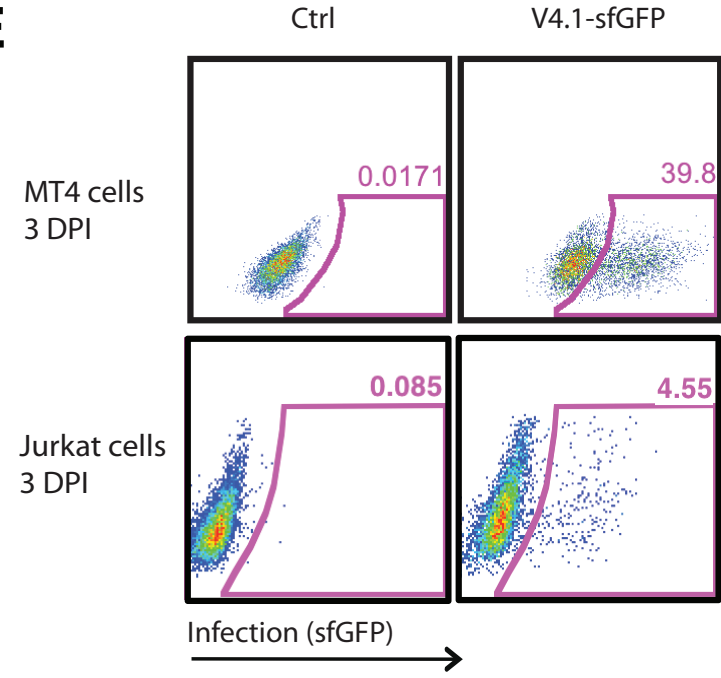

$\mathbf{F}$

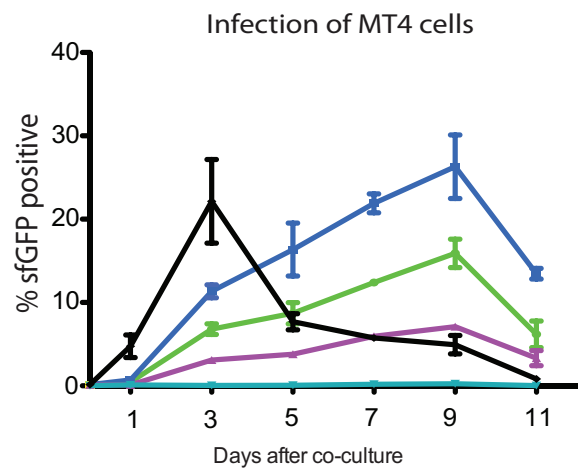

G Infection of Jurkat cells

anti-GFP
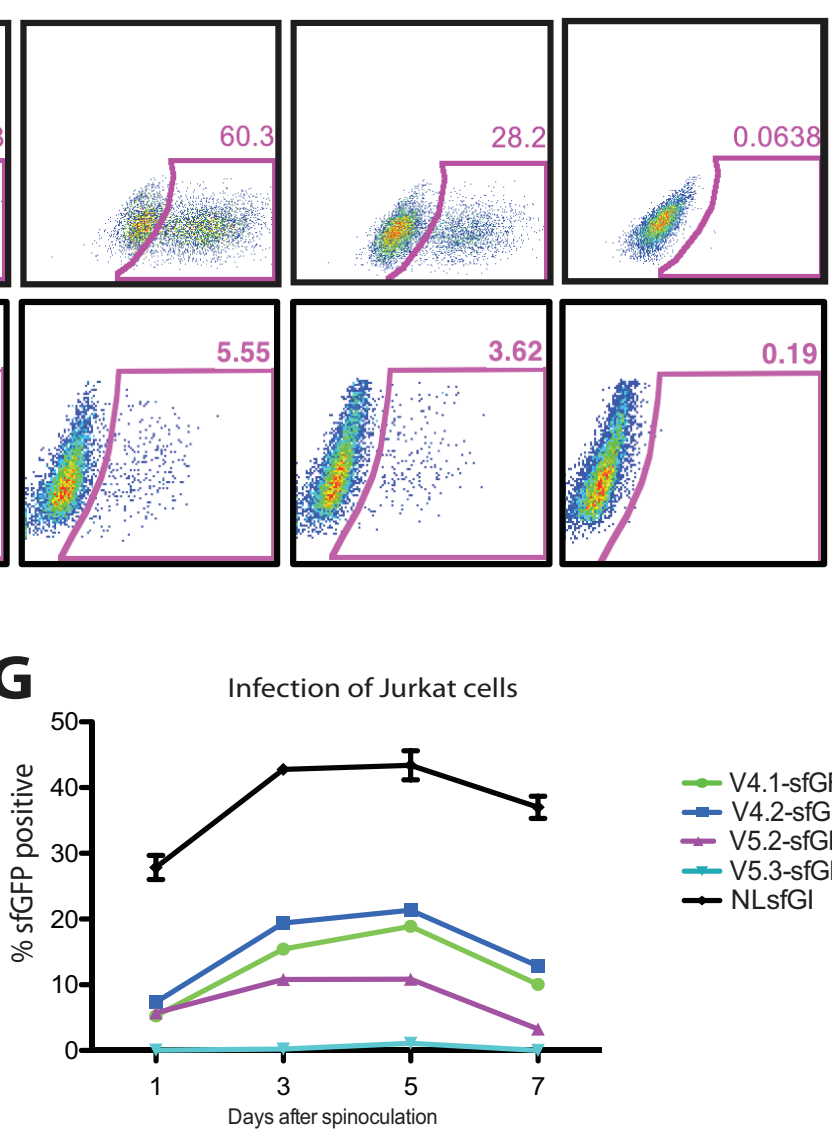

$\because V 4.1-$ sfGFP

$-\mathrm{V} 4.2$-sfGFP

- V5.2-sfGFP

- V5.3-sfGFP

- NLsfGI 
Figure 3

A

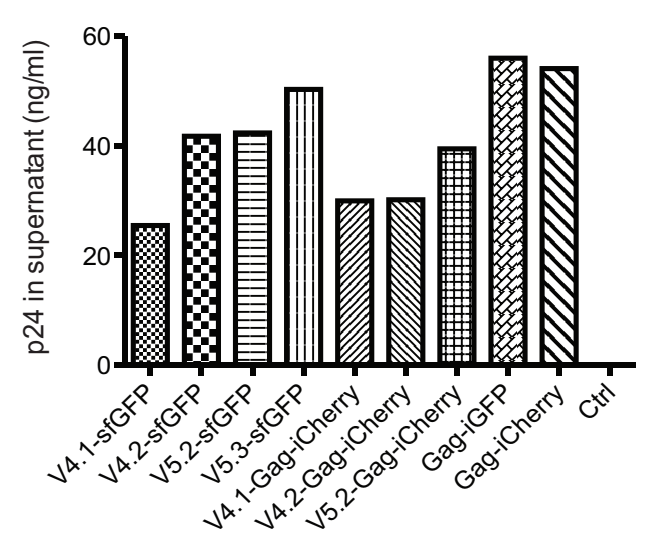

B

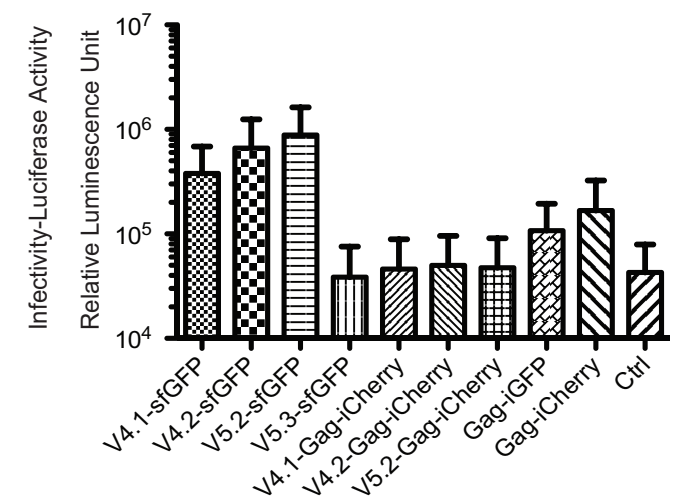

E
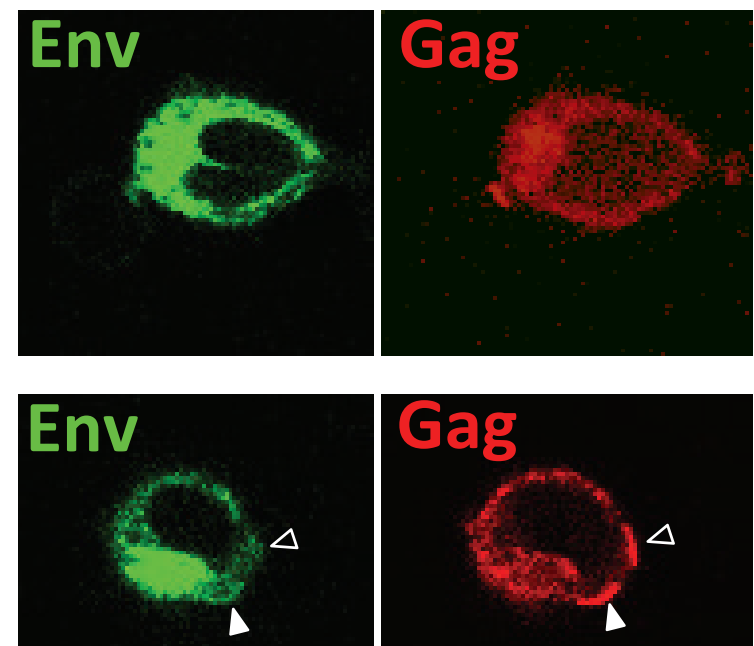

C

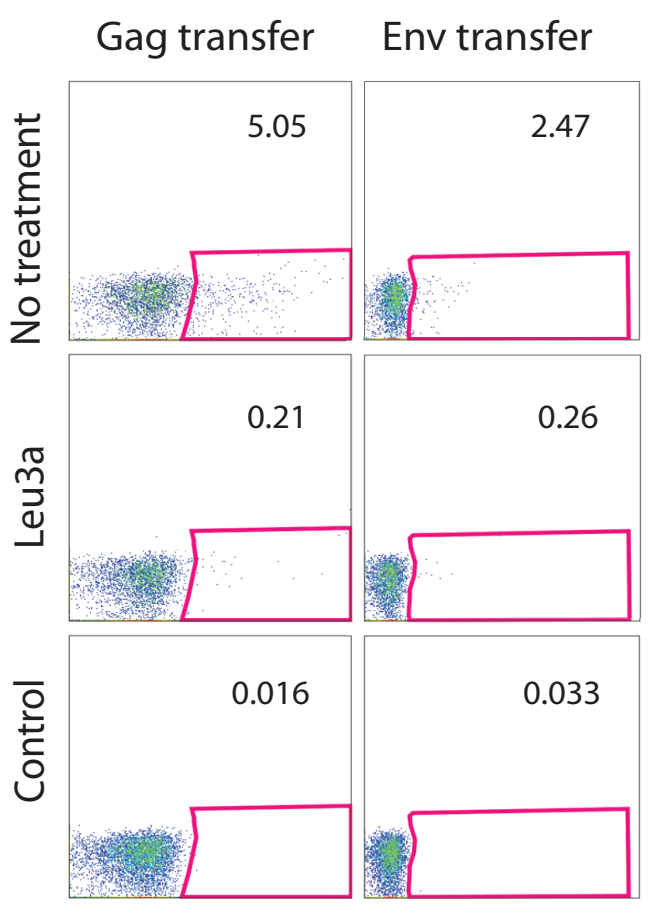

D
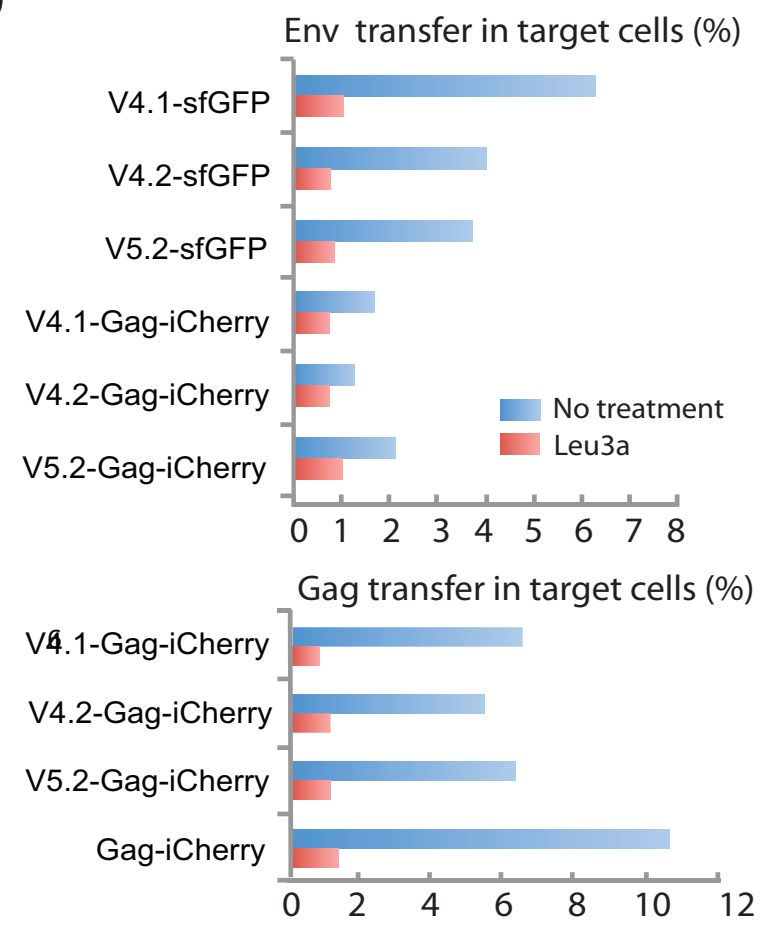

G
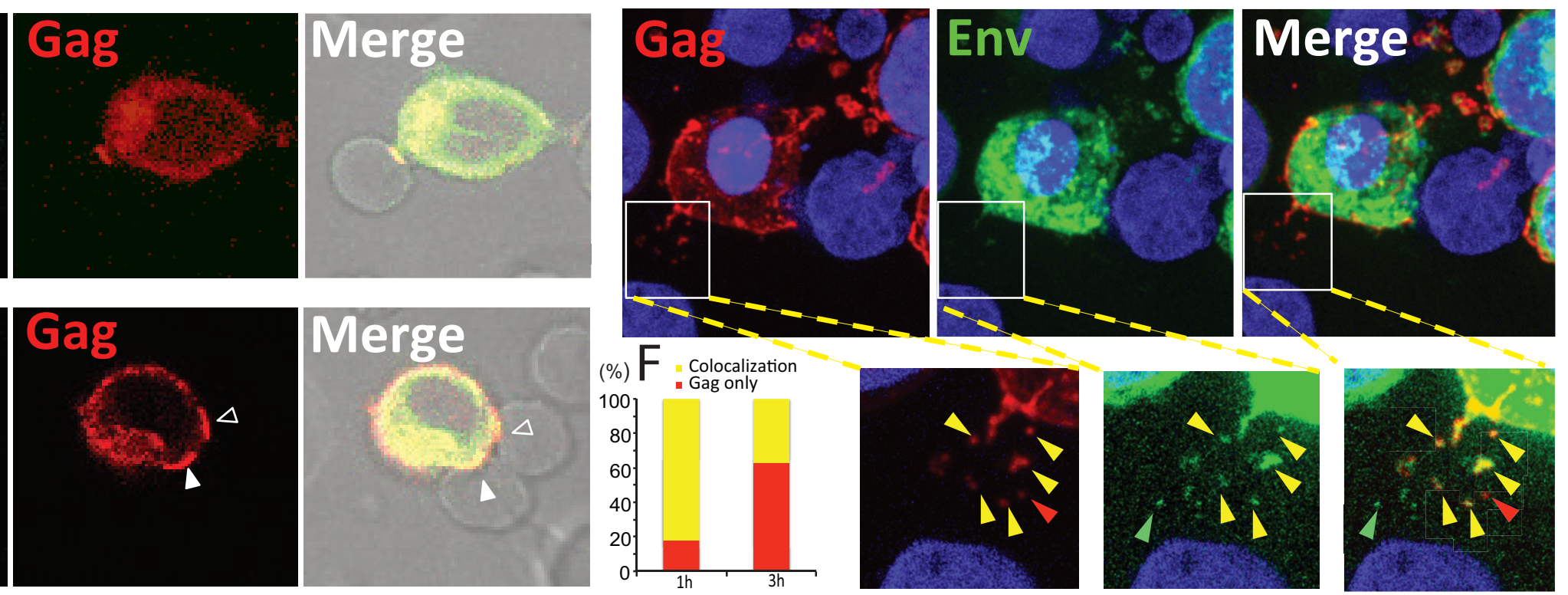


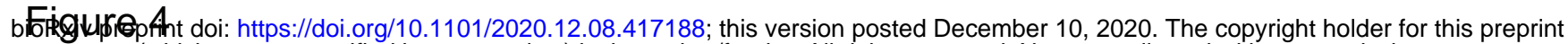
(which was not certified by peer review) is the author/funder. All rights reserved. No reuse allowed without permission.
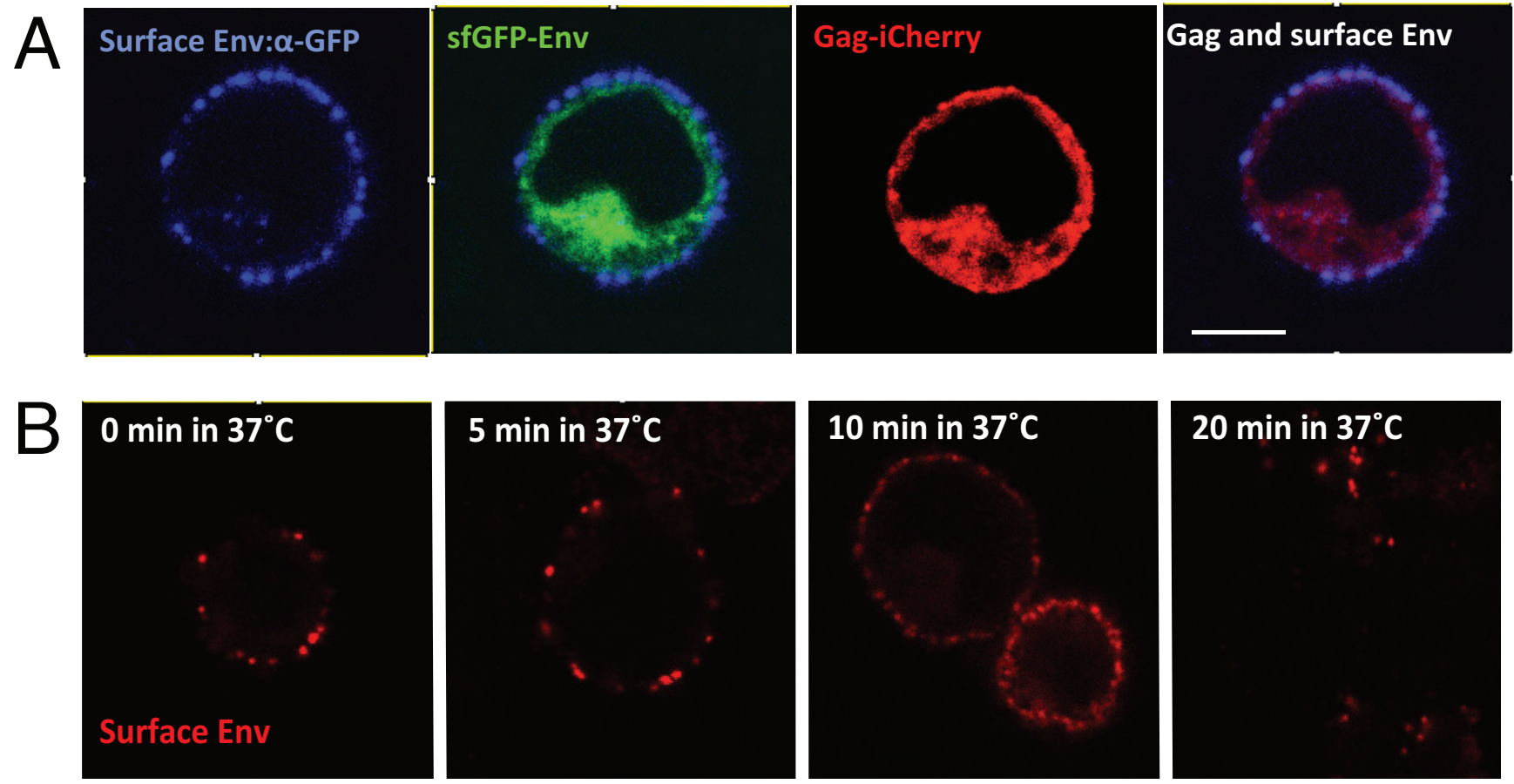

$20 \min$ in $37^{\circ} \mathrm{C}$

Surface Env

sfGFP-Env
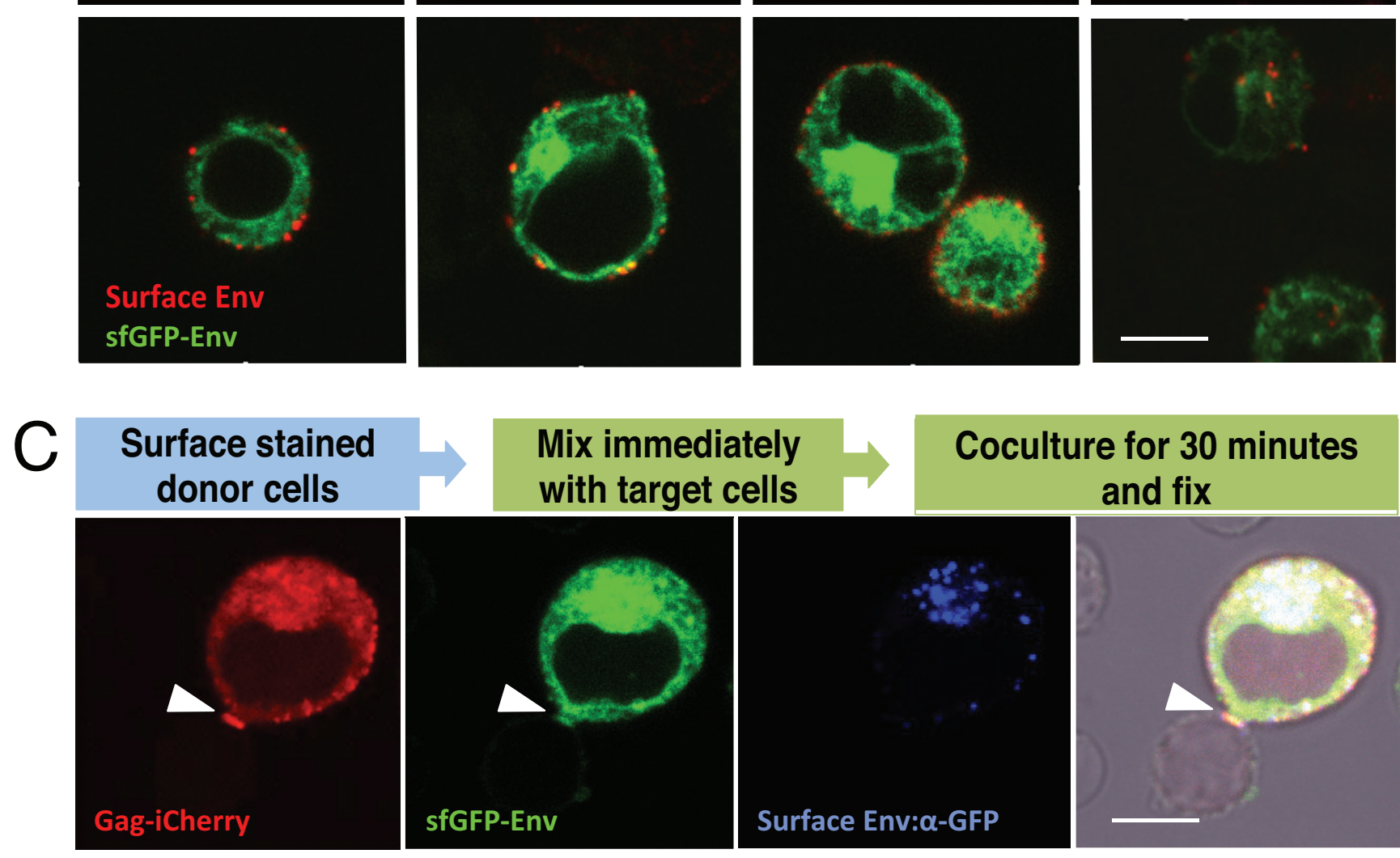

Surface Env:Q-GFP

\section{Coculture for 30 minutes and fix}
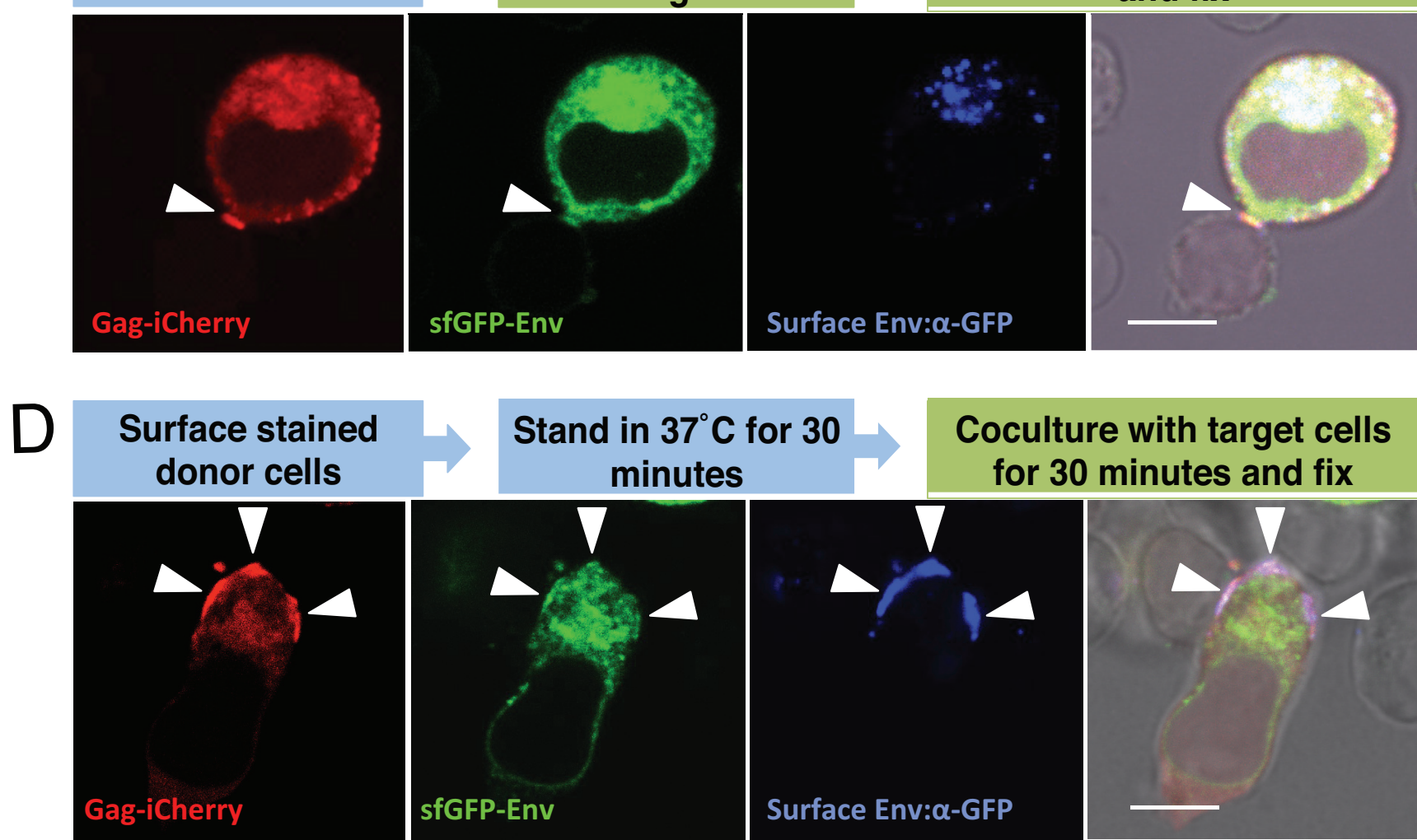
Figure 5oioRxiv preprint doi: https://doi.org/10.1101/2020.12.08.417188; this version posted December 10, 2020. The copyright holder for this preprint
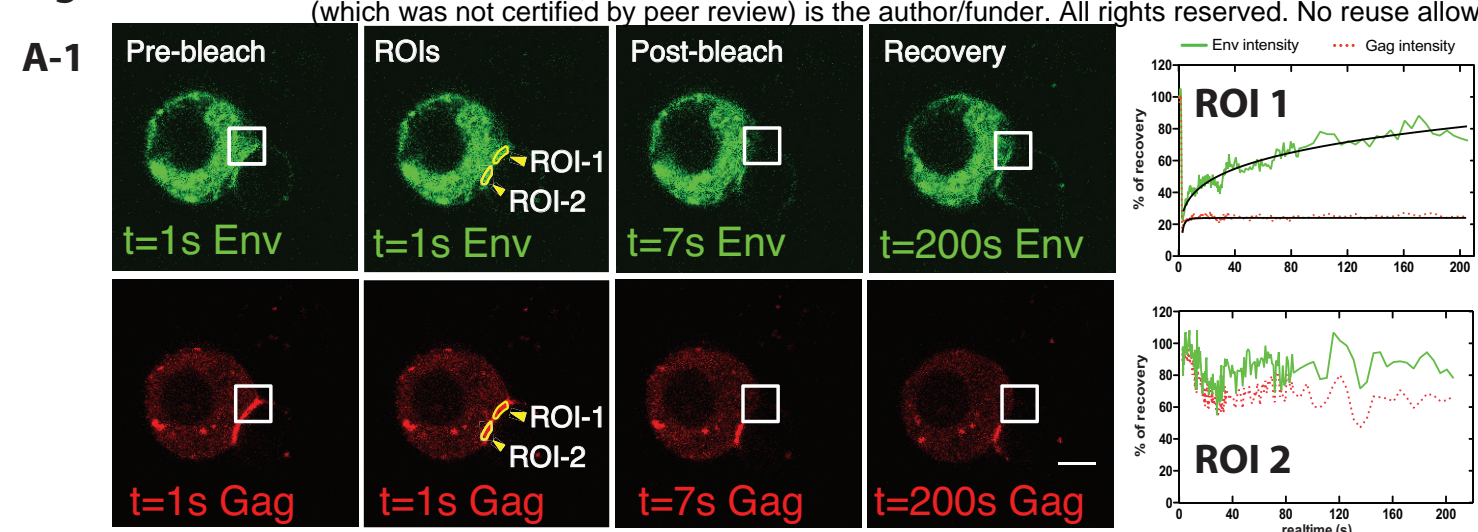
without permission.

\section{A-2}
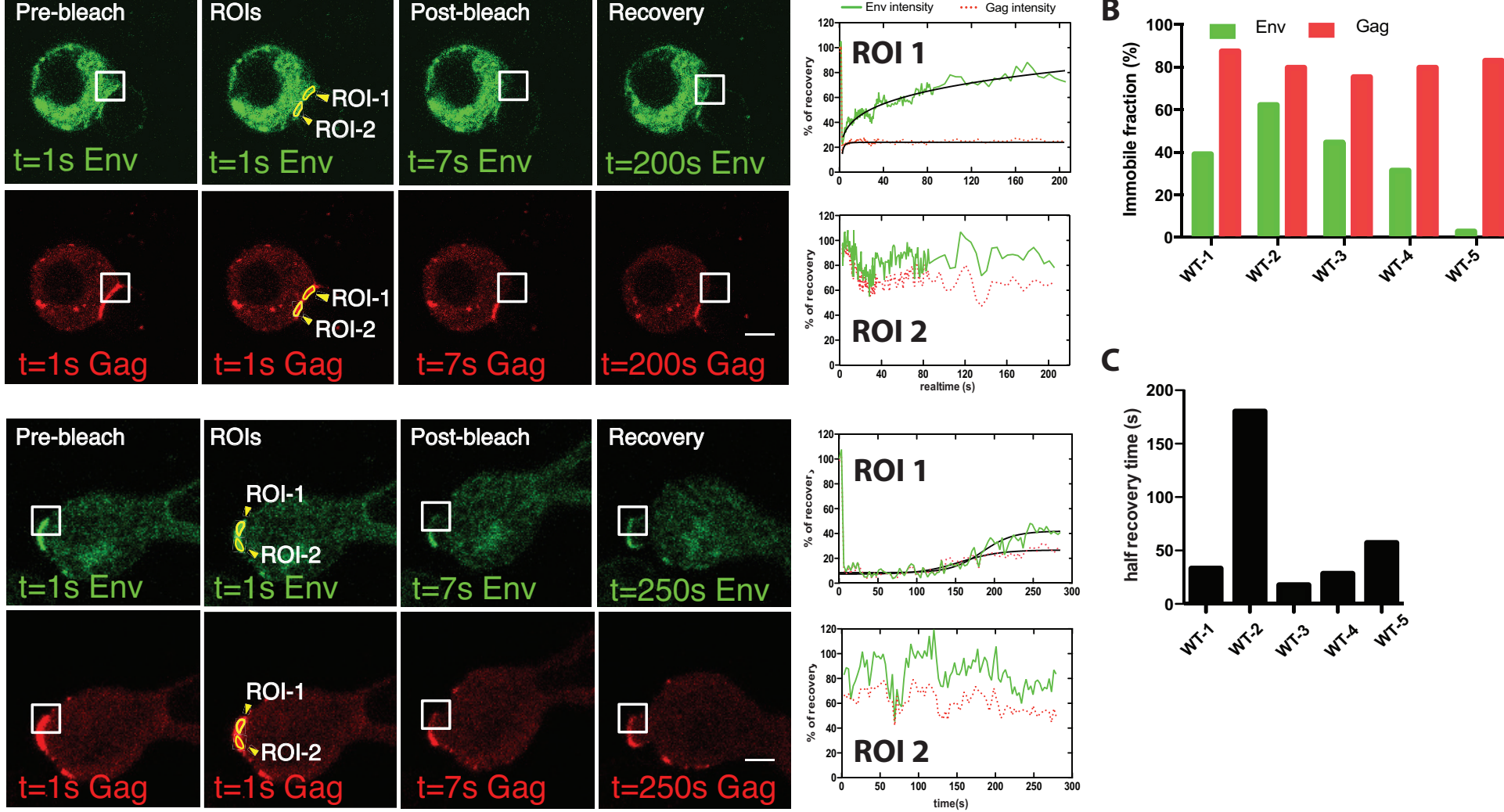

C

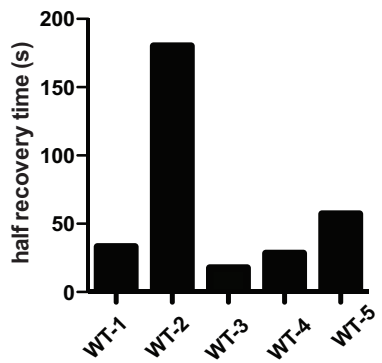

A-3
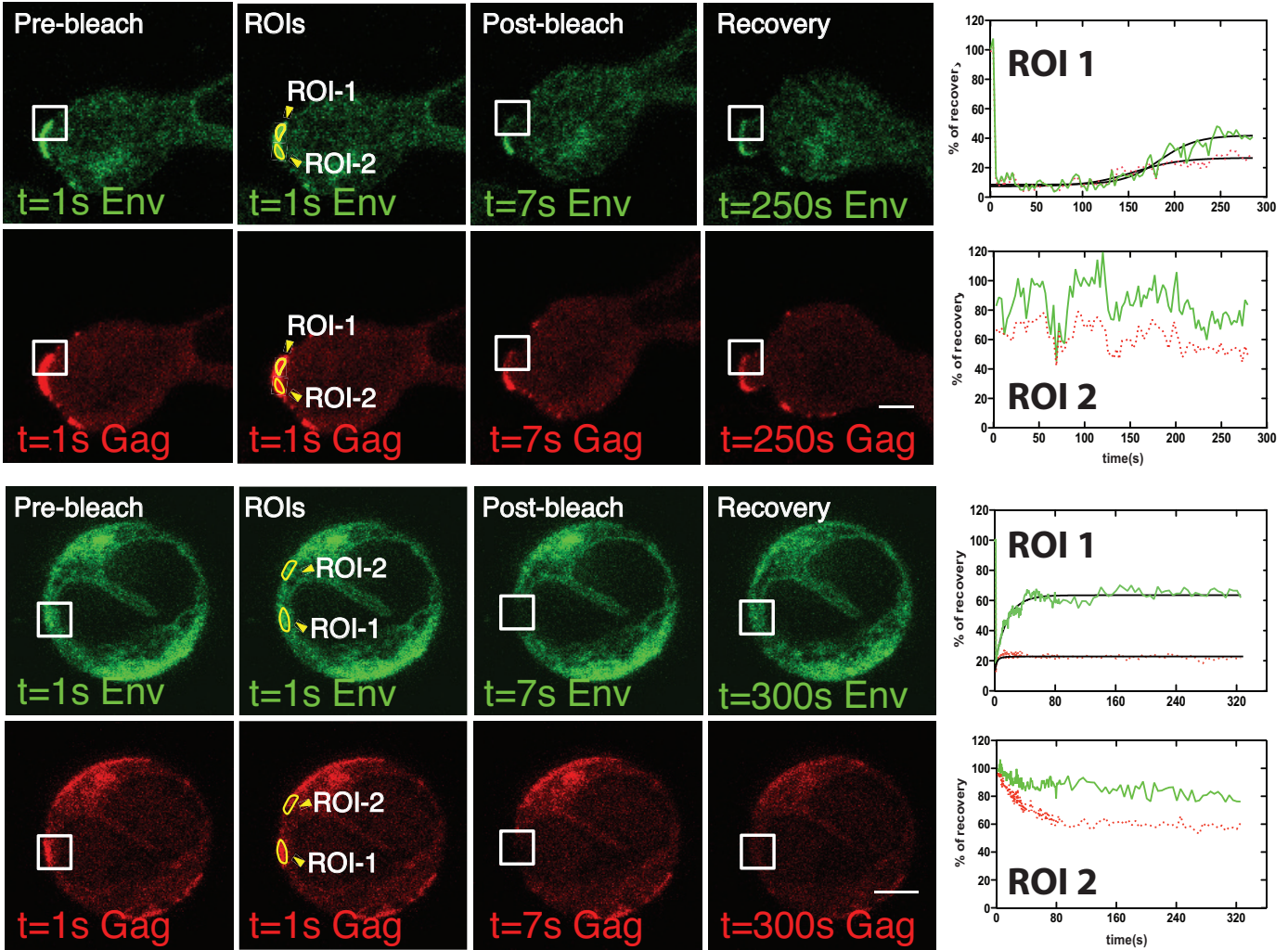

\section{A-4}
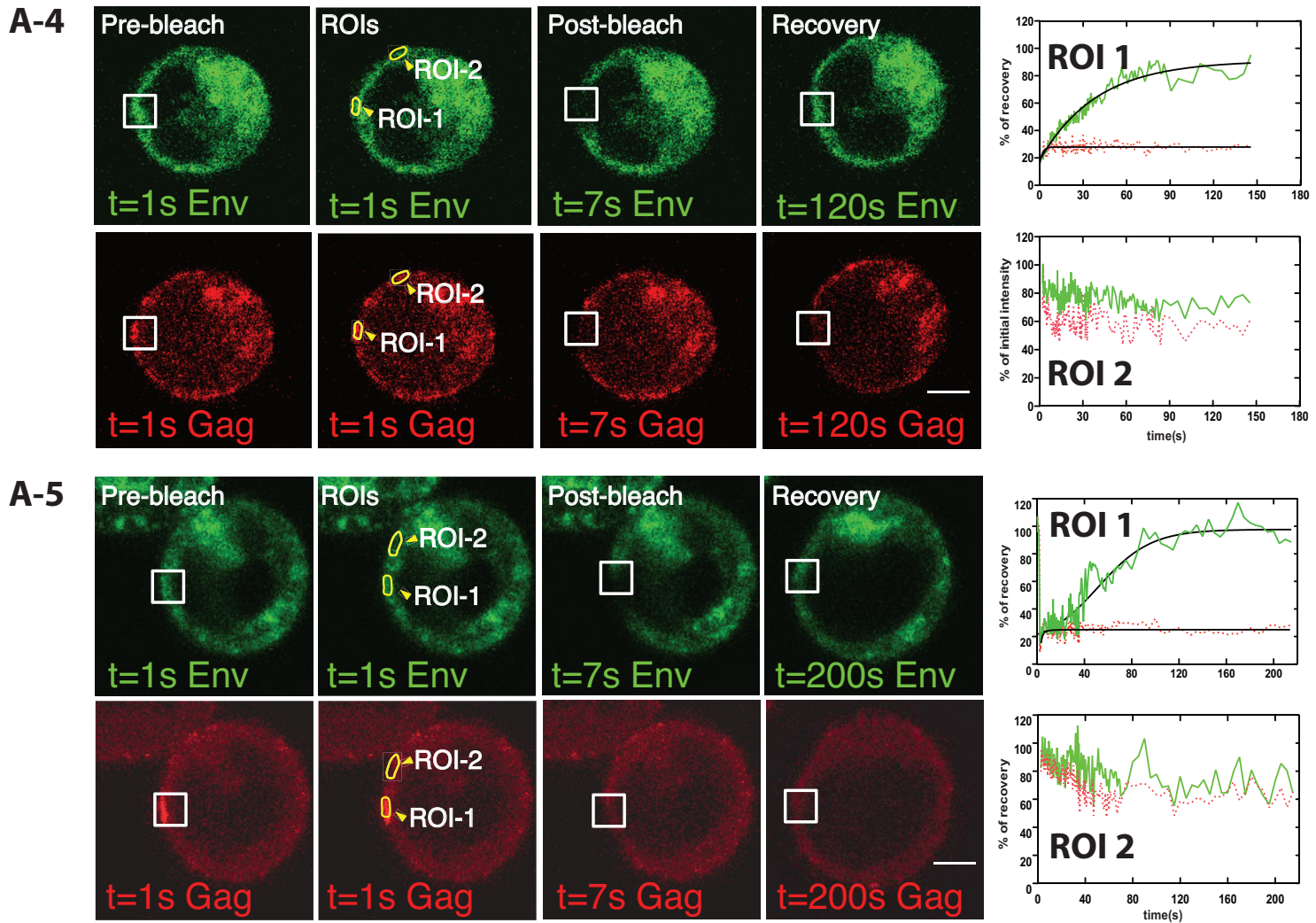
bioRxiv preprint doi: https://doi.org/10.1101/2020.12.08.417188; this version posted December 10, 2020. The copyright holder for this preprint (which was not certified by peer review) is the author/funder. All rights reserved. No reuse allowed without permission.

Figure 6
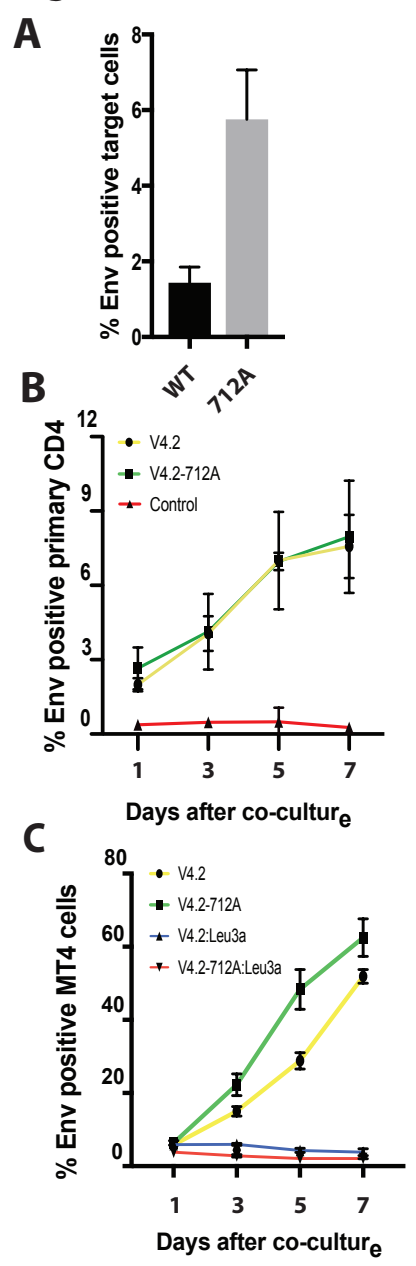

E

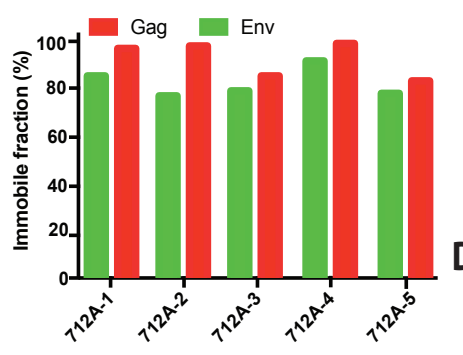

D-1

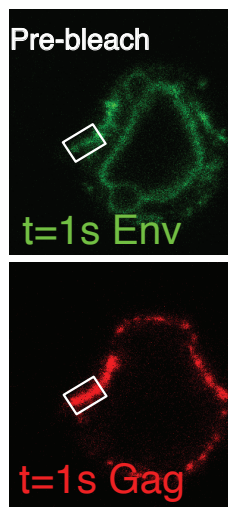

D-2

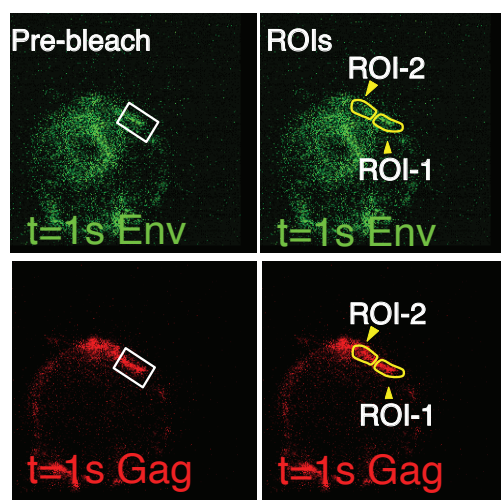

D-3
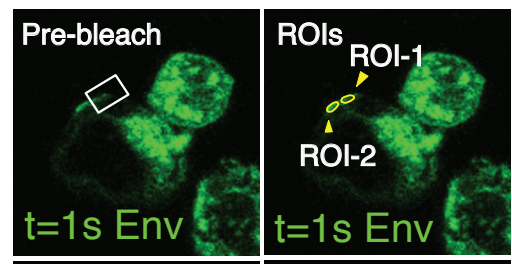

$\Delta$

t=1s Gag

D-4
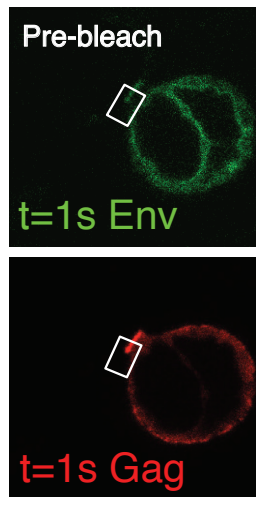

D-5
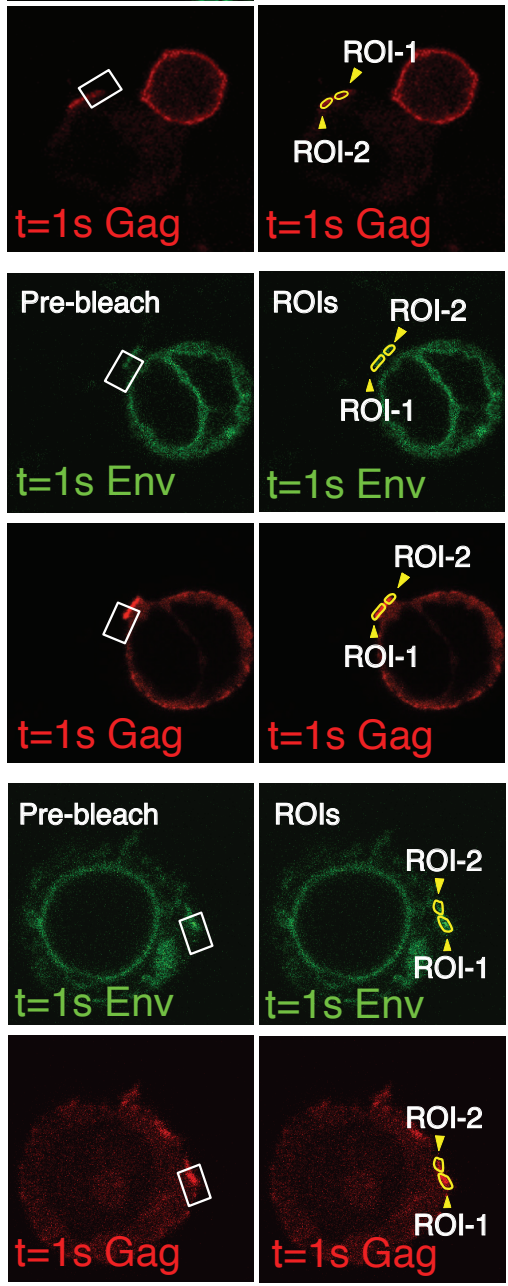
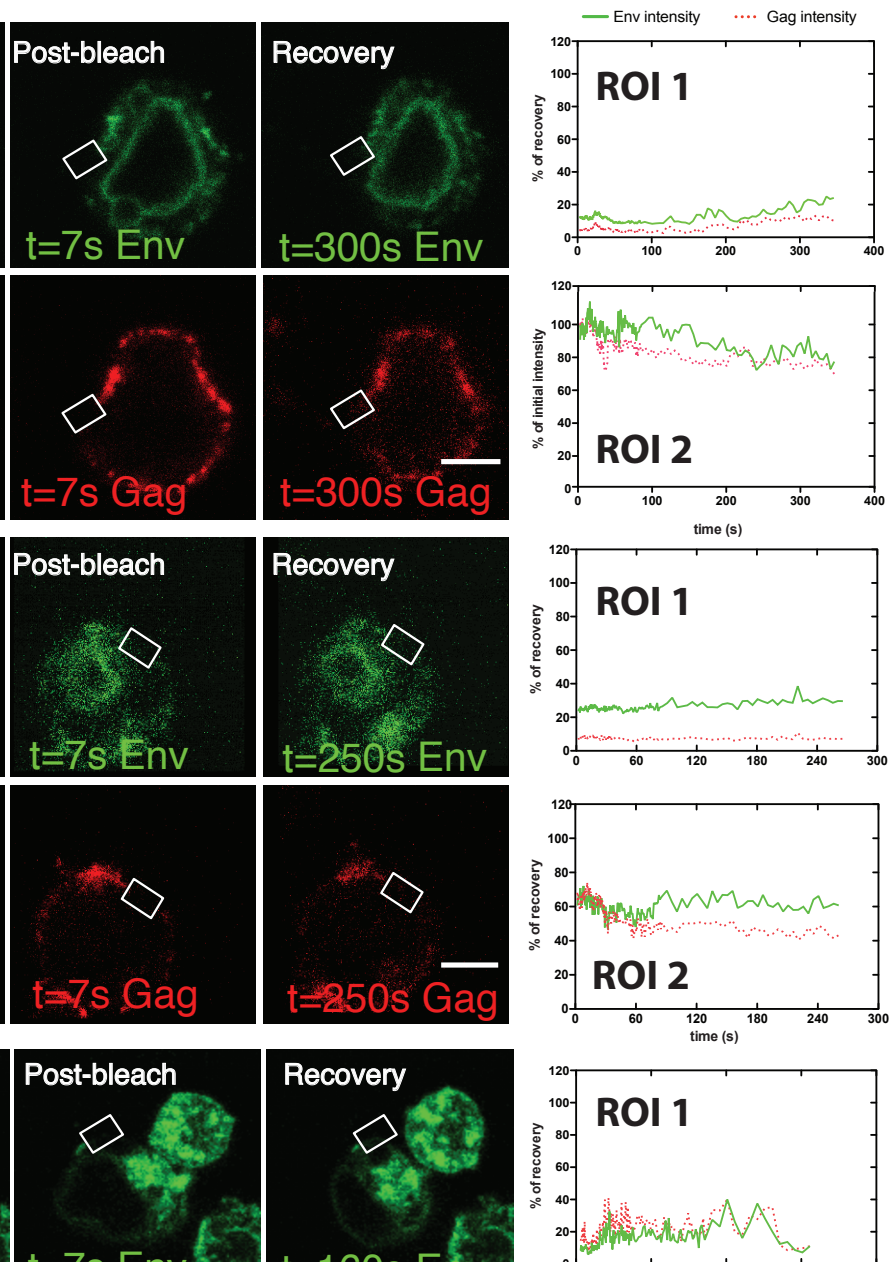

$\mathrm{t}=7 \mathrm{~s}$ Env

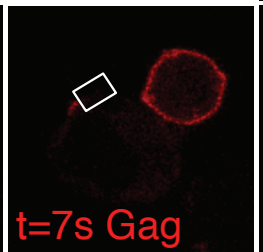

$t=160$ s Env
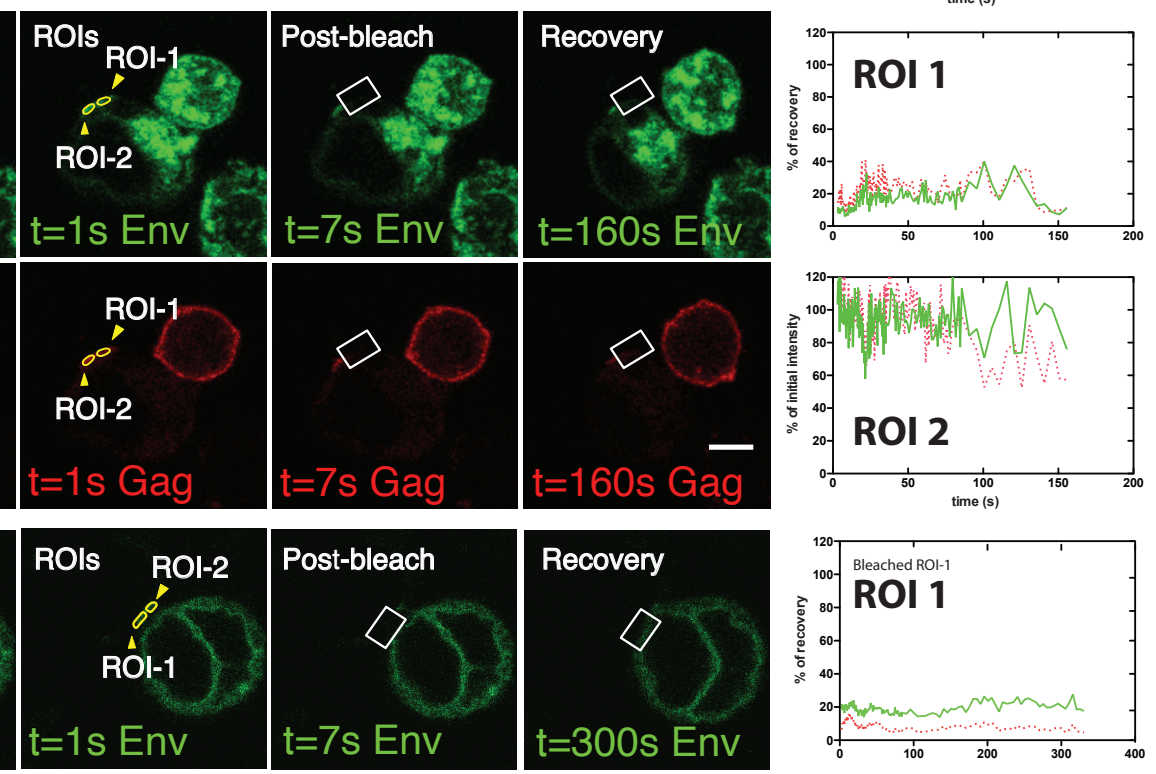

Recovery

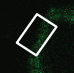

$\mathrm{t}=300 \mathrm{~s}$ Env
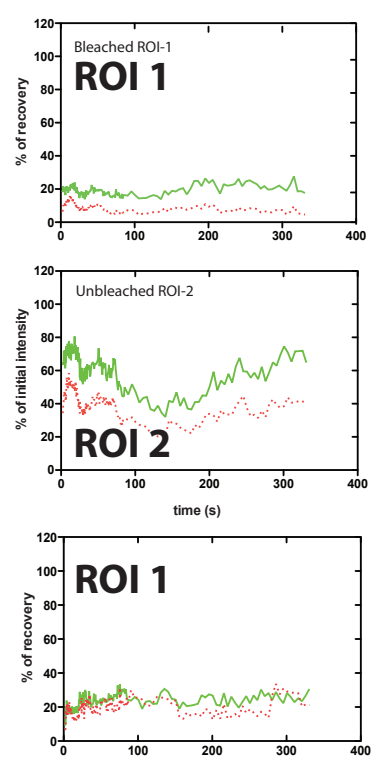

$t=300$ s Env
Post-bleach

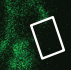

D

$\mathrm{t}=7 \mathrm{~s}$ Env
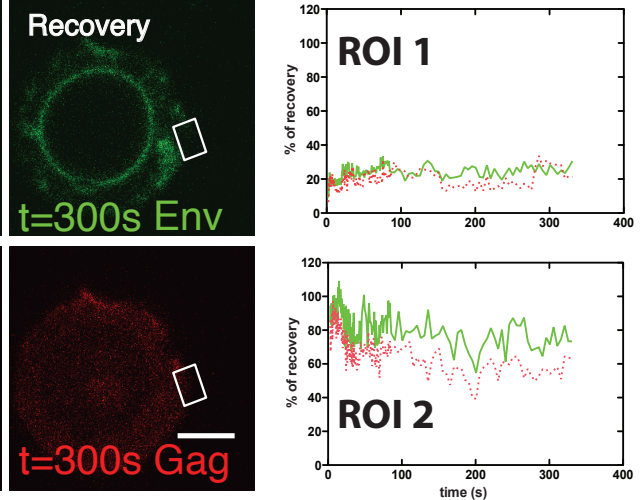
Figure 7

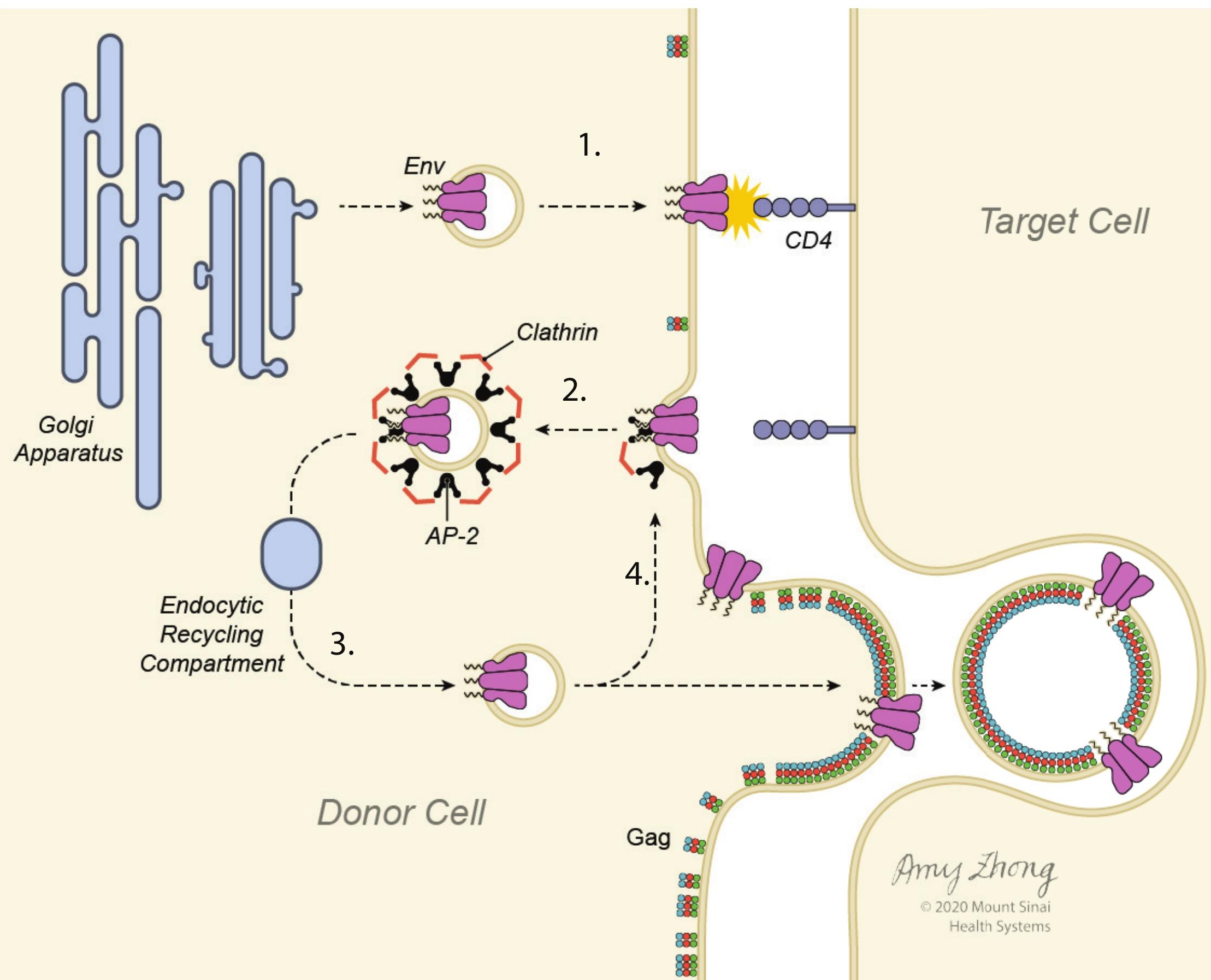

